
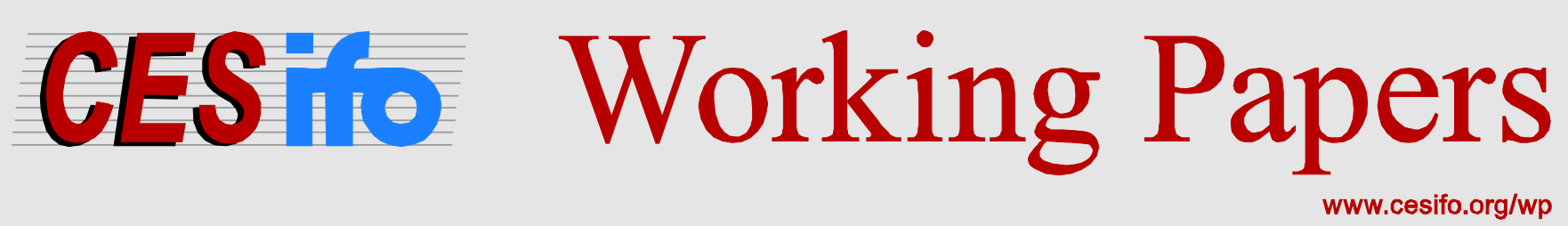

\title{
Coordinating Intergenerational Redistribution and the Repayment of Public Debt
}

\author{
Christoph March \\ Robert K. von Weizsäcker
}

CESIFO WORKING PAPER NO. 6075

CATEGORY 1: PUBLIC FinANCE

SEPTEMBER 2016

An electronic version of the paper may be downloaded

- from the SSRN website:

- from the RePEc website:

- from the CESifo website:

www.SSRN.com

www.RePEc.org

www.CESifo-group.org/wp 


\title{
Coordinating Intergenerational Redistribution and the Repayment of Public Debt
}

\begin{abstract}
Is there a link between public debt and wealth inequality? Could government bondholders use intra-generational redistribution strategically to make the repayment of debt politically viable? Using a two-generations game-theoretic model, we identify coordination and divide-andconquer as key factors. By coordinating their bond investments, the old generation may secure a majority favoring debt repayment. As a consequence, coordination mediates the impact of wealth inequality on public debt. Furthermore, ease of coordination offers another compelling reason why declining population growth fosters the accumulation of public debt. We test our model in a laboratory experiment and confirm the central predictions.
\end{abstract}

JEL-Codes: H230, H630, D720, C920.

Keywords: government debt, intergenerational conflict, voting, experimental economics.

Christoph March*

TU Munich

Arcisstraße 21

Germany - 80333 Munich

christoph.march@tum.de
Robert K. von Weizsäcker

TU Munich

Arcisstraße 21

Germany - 80333 Munich

weizsaecker@tum.de

*corresponding author

August 18, 2016

We thank Thomas Daske, Christian Feilcke, Marco Sahm, and seminar audiences at Technical University of Munich and LMU Munich for helpful comments and suggestions. We also thank Melanie Bader, Christoph Gschnaidtner, Julian Hackinger, Florian Inderst, Leonard Przybilla, and Alexander Schlimm for excellent research assistance. 


\section{Introduction}

In the wake of the Great Recession of 2008/2009, countries around the globe accumulated massive amounts of government debt. Figure 1 provides an overview for selected developed countries. Adjusting this unsustainable fiscal situation is among the main fiscal policy challenges of the near future. Yet, fiscal policy before the crisis casts serious doubts upon a successful fiscal adjustment process. Contrary to the prescriptions of optimal debt policies (e.g. Barro, 1979; Startz, 1989), governments persistently accumulated debt in peace time. As convincingly argued by a large and growing literature, politics is at the heart of this problem (see Alesina and Passalacqua, 2015; Weizsäcker, 1992, 2015).

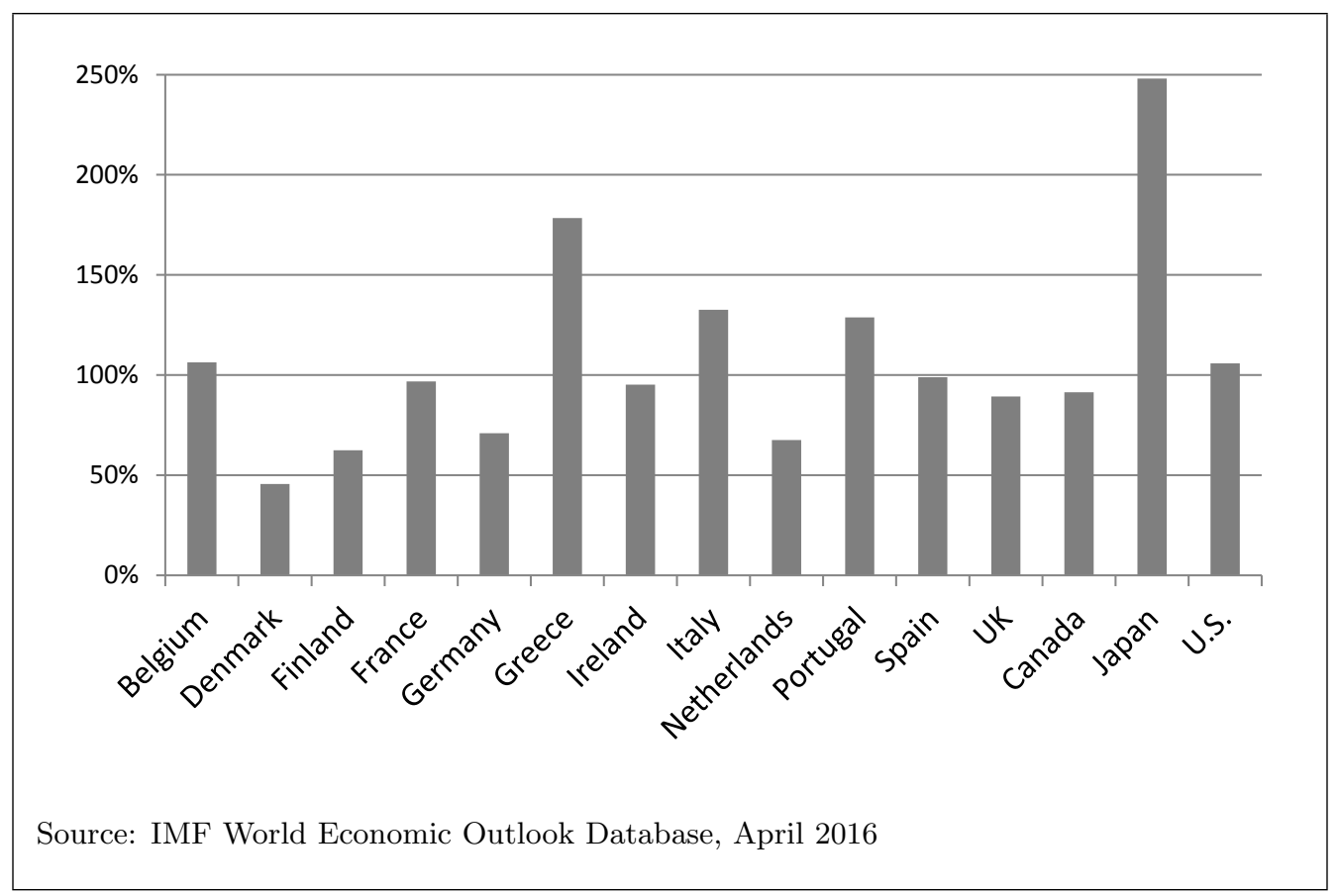

Figure 1:Ratio of Public Debt to GDP for Selected Countries

A special feature of government debt is the associated promise of transfers from future to current generations usually made without the consent of the former. This raises the question why these promises are kept. Tabellini (1991) shows that repudiating the debt affects both the inter- and the intragenerational distribution of resources. Concretely, debt repudiation does not affect all members of the old generation in the same way as it harms the wealthy more than the poor. Intergenerational altruism, or equivalently inheritance, then implies that the children of the wealthiest debt holders join the old in a coalition which supports repayment of debt. The central aspect of Tabellini's paper is the link between inter- and intragenerational redistribution, "a topic which is surprisingly understudied both theoretically and empirically" (Alesina and Passalacqua, 2015, p.34).

In this paper, we investigate how the link between inter- and intragenerational redistribution may be used strategically to make the repayment of debt politically viable. More precisely, we study when and how the old generation can exploit this link to its advantage. 
By developing a simple two-period, two-generations game-theoretic model, we identify the strategic challenge of the old generation and we show that exploiting intragenerational redistribution requires the old to resolve a coordination problem. Our model highlights that, when successful, the old generation effectively employs a divide-and-conquer strategy towards the young generation. In addition, the game-theoretic representation enables us to experimentally test Tabellini's (1991) redistributive mechanism.

Our paper makes several contributions: First, it adds coordination as an important aspect of intergenerational redistribution. We identify properties of the distribution of bond investments that make the repayment of debt politically viable (Proposition 1). The old generation may generate those properties by coordinating investments. We then show how coordination is affected by wealth inequality within the old generation. Specifically, we identify a property of the wealth distribution that enables a strategically simple and, under mild additional conditions, unique way of coordinating debt repayment (Proposition 3 and 4). Thus, the paper explicitly addresses the impact of inequality on government debt decisions (see e.g. Larch, 2012). The model also enables us to discuss other factors of debt repayment, namely population growth and inheritance laws.

Second, the model identifies divide-and-conquer as the driving force of intergenerational redistribution. While ex ante the young generation is opposed to issuing debt, successful coordination enables the old to form a coalition with some of the young voters. This insight connects our paper to a wide literature in political economics (see Section 2). Drawing on this literature enables us to shed new light on e.g. the role of budgetary institutions and constitutional reform. We also extend the theoretical basis of this literature by adding coordination as a prerequisite for divide-and-conquer.

Third, our experimental results shed light on the behavioral relevance of the redistributive mechanism. We find that (i) the divide-and-conquer strategy is successfully employed both if coordination is easy and if it is difficult, (ii) individuals vote truthfully in a large majority of cases, and (iii) individuals' concerns for both efficiency and fairness affect the success of redistribution and debt repayment and should therefore be taken into account.

Finally, we provide an experimental paradigm to investigate the interplay between redistribution, coordination, and divide-and-conquer. Empirical studies on fiscal policy in general, and government debt and inequality in particular, are plagued by problems of data availability, measurement, and causality. It is not clear, for example, how a binding vote on debt repudiation could be organized in practice. ${ }^{1}$ Experiments have the potential to overcome some of these issues and to stimulate future empirical studies (see also Sutter, 2003).

The paper is structured as follows: Section 2 discusses related literature. Section 3 introduces the game-theoretic model and derives the equilibria. Section 4 presents the experimental results. Section 5 concludes. The appendix contains the proofs, complementary statistical results, and the experimental instructions.

\footnotetext{
${ }^{1}$ The case of Greece provides a good example of the difficulties involved.
} 


\section{Related Literature}

The paper relates to a wide literature in public finance, political, and experimental economics.

First, we contribute to the political-economic literature on the strategic use of budget deficits. This literature explains deviations from optimal debt policy by strategic considerations of politicians and voters. The literature may be broadly categorized according to the underlying strategic motives (see e.g. Eslava, 2011; Weizsäcker, 2015): Opportunistic policymakers seeking re-election (early contributions are Nordhaus, 1975; Buchanan and Wagner, 1977), partisan incumbents attempting to bind their successors (Alesina and Tabellini, 1990; Tabellini and Alesina, 1990), policymakers facing a common pool problem (Weingast, Shepsle, and Johnsen, 1981; Baron and Ferejohn, 1989), and current generations exploiting the possibility to redistribute from future generations to themselves (Tabellini, 1991; Song, Storesletten, and Zilibotti, 2012). Our paper addresses the latter and its connection to intragenerational redistribution.

Second, we extend the literature on divide-and-conquer. In a nutshell, divide-andconquer refers to the use of discrimination and favoritism to exploit a group that could withstand by acting unanimously. This tactic has been identified as a building block of Roman imperialism (Abbott, 1901). In recent years, several papers have applied this idea to a wide array of topics, e.g. international relations (Wagner, 1986), market entry deterrence (Rasmussen, Ramseyer, and Wiley, 1991; Segal and Whinston, 2000), kleptocracy (Acemoglu, Robinson, and Verdier, 2004), constitutional design (Weingast, 1995, 1997, 2005), litigation (Che and Spier, 2008), and multi-sided markets (Jullien, 2011). An overview is provided by Posner, Spier, and Vermeule (2010). Many of this literature's insights on divide-and-conquer can be useful in the context of redistribution and government debt. For example, we draw on this literature to discuss the role of constitutional rules. A common feature of the studies cited above is the assumption that the divide-andconquer strategy is employed by a single actor (see however Eavey and Miller, 1995). Our model extends the literature by identifying a so far neglected prerequisite for a successful implementation of divide-and-conquer, namely coordination.

Finally, our paper relates to several strands of the experimental literature. The strategic use of budget deficits has mainly been addressed by Sutter (2003), who tests the partisan model of Alesina and Tabellini (1990) and finds support for its predictions. ${ }^{2}$ A growing literature studies divide-and-conquer in the laboratory. Landeo and Spier (2009) and Boone, Müller, and Suetens (2014) confirm the use of divide-and-conquer in the strategic context of Rasmussen, Ramseyer, and Wiley (1991) and Segal and Whinston (2000). Cason and Mui $(2007,2014,2015)$ investigate how communication and repeated interaction help the majority coordinate to resist divide-and-conquer in the three-player transgression game of Weingast $(1995,1997)$. Divide-and-conquer has also been investigated in extensions of

\footnotetext{
${ }^{2}$ See also Irlenbusch and Sutter (2006), who show that voting rules of the Stability and Growth Pact in the European Monetary Union may be used strategically by larger countries to run excessive deficits.
} 
the ultimatum game (Messick, Moore, and Bazerman, 1997; Elbittar, Gomberg, and Sour, 2011), and in the context of committee bargaining (e.g. Eavey and Miller, 1984; Eavey, 1987; Frechette, Kagel, and Morelli, 2005, see Palfrey, 2013 for a comprehensive overview). Contrary to all these studies, divide-and-conquer may only be implemented by a group of subjects in our experiment, which necessitates coordination. The only other study with this feature we are aware of is Eavey and Miller (1995) on subcommittee bargaining. In that study, however, subjects are allowed to bargain freely, and repeated coordination within changing coalitions is necessary to reach the predicted outcome.

\section{A Game-Theoretic Model}

\subsection{The Intergenerational Redistribution Game}

There are two periods, $t=1,2$, and two generations of players. Players in the parent generation are denoted by $i=1, \ldots, I$ where $I \geq 2$, and each of them has $n \in \mathbb{N}$ children. We frequently refer to the parent (child) generation as the old (young).

In period 1, parent $i$ is endowed with the privately-observed individual wealth $e_{i}>0$ drawn from a (commonly) known distribution with cumulative distribution function $G(\cdot)$. The parent then decides about her investment $s_{i} \in S_{i} \subset\left[0, e_{i}\right]$ in government bonds, which yields a secure gross rate of return $r>1$. For simplicity we assume that $S_{i}=$ $\left\{0, d, 2 d, \ldots, e_{i}\right\}$ for each $i$ where $d$ is an indivisible monetary unit (hence $e_{i} / d \in \mathbb{N}$ for all $i)$. The profile of investments $s=\left(s_{1}, \ldots, s_{I}\right)$ is publicly observed, and it is used to finance a public good of size $g=\sum_{i} s_{i}$.

Repayment of government debt (with interest) is due in period 2. To repay the debt, the government collects income taxes from the children, since only children earn income in period 2. We assume the latter to be constant across individuals and equal to $w .^{3}$ However, debt may also be fully or partially repudiated. To determine the fraction of debt that is repaid, parents and children vote on the repayment rate $\theta \in[0,1]$. Conversely, $1-\theta$ denotes the repudiation rate or, put differently, the extent of the haircut that is invoked. ${ }^{4}$

Denote by $\theta_{i}\left(\theta_{i j}\right)$ the repayment rate voted on by parent $i$ (parent $i$ 's $j$ th kid). To simplify the analysis, we assume that $\theta_{i}, \theta_{i j} \in \Theta=\{\underline{\theta}, \bar{\theta}\}$ with $0 \leq \underline{\theta}<\bar{\theta} \leq 1$. Given the vectors of votes $\boldsymbol{\theta}_{p}=\left(\theta_{1}, \ldots, \theta_{I}\right)$ and $\boldsymbol{\theta}_{c}=\left(\theta_{i 1}, \ldots, \theta_{i n}\right)_{i=1}^{I}$, the repayment rate is selected by majority rule; formally

$$
\theta \equiv \theta\left(\boldsymbol{\theta}_{p}, \boldsymbol{\theta}_{c}\right)=\min \left[\arg \max _{\hat{\theta} \in\{\underline{\theta}, \bar{\theta}\}}\left(\sum_{i=1}^{I} \mathbb{1}_{\{\hat{\theta}\}}\left(\theta_{i}\right)+\sum_{i=1}^{I} \sum_{j=1}^{n} \mathbb{1}_{\{\hat{\theta}\}}\left(\theta_{i j}\right)\right)\right]
$$

\footnotetext{
${ }^{3}$ Extending the model to allow for heterogeneous income of the children yields qualitatively similar results, but is notationally cumbersome. Results are available from the authors upon request.

${ }^{4}$ Tabellini (1991) labels $1-\theta$ the tax rate on debt.
} 
where $\mathbb{1}_{A}(\cdot)$ is the indicator function of set $A .{ }^{5}$ Accordingly, the first (second) sum on the right-hand side is the number of parents' (children's) votes in favor of repayment rate $\hat{\theta}$. The RHS also specifies that in case of a tie the lower repayment rate is selected. Hence, the high repayment rate $\bar{\theta}$ must be supported by a strict majority.

The voting outcome $\theta$ and the sum of investments jointly determine the income tax rate $\tau$ through the government budget constraint $\theta r \sum_{i} s_{i}=\tau n I w$. Hence, $\tau$ depends on the voting outcome and the average investment $\bar{s}=\frac{1}{I} \sum_{i=1}^{I} s_{i}$ via

$$
\tau=\frac{\theta r \sum_{i} s_{i}}{n I w}=\frac{r \bar{s}}{n w} \theta .
$$

The investment profile $\boldsymbol{s}$ and the voting profile $\left(\boldsymbol{\theta}_{p}, \boldsymbol{\theta}_{c}\right)$ jointly determine the outcome of the game and the payoffs of parents and children. Concretely, parent $i$ 's payoff is

$$
\pi_{i}\left(s, \boldsymbol{\theta}_{p}, \boldsymbol{\theta}_{c}\right)=e_{i}-s_{i}+\gamma_{p} \sum_{i=1}^{I} s_{i}+\alpha_{p} \theta r s_{i}
$$

where $\gamma_{p} \in[0,1)$ denotes the extent to which the public good benefits the parents, and $\alpha_{p}>0$ denotes the degree to which parents benefit from their own investment. The payoff of parent $i$ 's $j$ th kid is

$$
\begin{aligned}
\pi_{i j}\left(\boldsymbol{s}, \boldsymbol{\theta}_{p}, \boldsymbol{\theta}_{c}\right) & =(1-\tau) w+\gamma_{c} \sum_{i=1}^{I} s_{i}+\alpha_{c} \theta r \frac{s_{i}}{n} \\
& =w+\gamma_{c} \sum_{i=1}^{I} s_{i}+\theta \frac{r}{n}\left[\alpha_{c} s_{i}-\bar{s}\right]
\end{aligned}
$$

where $\gamma_{c}>0$ denotes the degree to which the public good benefits the children, and $0 \leq \alpha_{c}<1$ denotes the fraction of the parent's investment which is inherited. The following lemma provides a rationale for the assumption $\alpha_{c}<1$.

Lemma 1. Ex ante, children prefer the low repayment rate if and only if $\alpha_{c}<1$.

We study the subgame perfect equilibria of the game with the restriction that equilibrium strategies are pure and not weakly dominated (equilibria henceforth). Together with the assumption that voters choose among two repayment rates, this ensures truthful voting, i.e. each individual votes in favor of the repayment rate that would maximize her payoff (Besley and Coate, 1997).

The assumption that only two alternatives are available is restrictive. Notice however that the parents' payoffs are increasing in $\theta$ and the payoffs of parent $i$ 's children are increasing (decreasing) in $\theta$ if $\alpha_{c} s_{i}>(<) \bar{s}$. Therefore, each voter either favors full repayment or full repudiation of the debt. This suggests that political platforms will converge towards those two extremes. Moreover, factors beyond the scope of the model may limit the extent to which the debt may be repudiated (or repaid). For example, a too extreme haircut severely limits a government's opportunities to borrow in the future (Cruces and Trebesch, 2013).

\footnotetext{
${ }^{5} \mathbb{1}_{A}(x)=1$ if $x \in A$, and $\mathbb{1}_{A}(x)=0$ if $x \notin A$
} 


\subsection{Voting and Divide-and-Conquer}

Our first result characterizes equilibrium voting.

Proposition 1. In any equilibrium, $\theta_{i}^{*}=\bar{\theta}$ for each $i=1, \ldots, I$, and

$$
\theta_{i j}^{*}\left(s_{i}^{*}\right)= \begin{cases}\bar{\theta} & \text { if } \alpha_{c} s_{i}^{*}>\bar{s}^{*} \\ \underline{\theta} & \text { if } \alpha_{c} s_{i}^{*}<\bar{s}^{*}\end{cases}
$$

for each $i=1, \ldots, I$ and each $j=1, \ldots, n$. Accordingly, $\theta^{*}=\bar{\theta}$ if and only if

$$
H\left(\frac{\bar{s}}{\alpha_{c}}\right)<\frac{1}{2} \frac{n+1}{n} .
$$

where $H(s)=\left|\left\{i: s_{i}<s\right\}\right| / I$ is the empirical distribution function of investments.

The proposition shows that the high repayment rate $\bar{\theta}$ is supported by (i) parents ${ }^{6}$ and (ii) the children of those parents who invested the most in government debt. Unless debt is fully repudiated, the latter are the wealthiest in the young generation. In contrast, poor children prefer the low repayment rate $\underline{\theta}$. Accordingly, debt repayment is supported by a coalition of the old and the wealthy young, as in Tabellini (1991).

The repayment of debt is politically viable if and only if the coalition of the old and the wealthy young holds the majority. Whether or not this will be the case depends on the distribution of bond investments within the old generation. The necessary and sufficient condition is given by (1) which states that the fraction of investments below $\bar{s} / \alpha_{c}$ is bounded above. In other words, the proportion of parents investing little to nothing in government bonds cannot be too large. Otherwise, the coalition of poor children is large enough to prevent the repayment of debt. Debt repayment is therefore politically viable only if the degree of inequality in the distribution of bond investments is limited. On the other hand, a uniform distribution of investments $\left(s_{i}=s\right.$ for each $\left.i=1, \ldots, I\right)$ also results in the low repayment rate, since $\bar{s} / \alpha_{c}>\bar{s}$ and therefore $H\left(\bar{s} / \alpha_{c}\right)=1>(n+1) /(2 n)$. In summary, debt can be held neither too widely nor too narrowly.

Note that the politically viable degree of inequality in the distribution of bond investments depends on the rate of population growth. For large $n$, a majority in favor of debt repayment only exists if the median of the distribution of bond investments is larger than its mean. The smaller $n$, the smaller is the fraction of parents holding the largest amount of the debt (equivalently the fraction of wealthy children) that is necessary to ensure debt repayment.

In the light of Lemma 1, whenever the coalition of the old and the wealthy young holds the majority, children effectively fall prey to a divide-and-conquer mechanism. Withstanding such a mechanism would require the young to cooperate and unite against the old. Weingast (2005) and Cason and Mui (2014, 2015) (among others) discuss possible solutions to this social dilemma. On the other hand, parents in our model may exploit the

\footnotetext{
${ }^{6}$ We assume that parents vote for the high repayment rate even when investing nothing to avoid cumbersome notation.
} 
possibility to divide-and-conquer to their advantage. We discuss this opportunity in the next sub-section where we show that successful divide-and-conquer requires the parents to resolve a coordination problem.

\subsection{Bond Investments and Coordination}

To characterize equilibrium investments and the coordination problem parents face, we distinguish two types of equilibria: A no-debt-equilibrium satisfies $s_{i}^{*}=0$ for each $i=$ $, 1 \ldots, I$. A debt-equilibrium satisfies $s_{i}^{*}>0$ for some $i \in\{1, \ldots, I\}$.

We first establish conditions under which government debt may not be issued in equilibrium since it will not be repaid. Let $\lceil x\rceil=\min \{z \in \mathbb{Z}: z>x\}$.

Proposition 2. A no-debt-equilibrium exists if and only if $\underline{\theta}<\frac{1-\gamma_{p}}{\alpha_{p} r}$ and at least one of the following conditions is satisfied: (i) $\bar{\theta}<\frac{1-\gamma_{p}}{\alpha_{p} r}$, (ii) $\alpha_{c}<\frac{1}{I}$, or (iii) $n(I-2)>I$. The no-debt-equilibrium is the unique equilibrium under condition (i), under condition (ii) if $n>1$, and under condition (iii) if $\alpha_{c}<\left\lceil\frac{1}{2} \frac{n-1}{n} I\right\rceil / I$.

The conditions are easily interpreted. First, parents invest in government bonds for sure, if the repayment rate is high regardless of the voting outcome. A no-debt-equilibrium thus requires the possibility to repudiate a sufficiently large fraction of the debt. Conversely, parents do not invest in government bonds in any equilibrium if the repayment rate is low irrespective of the voting outcome. Second, a no-debt-equilibrium exists, if children benefit little from parents' investments since this prevents the majority coalition supporting repayment of debt from forming. Third, a no-debt-equilibrium is easier to sustain if population growth is larger because the latter implies a smaller political influence of the older generation. Finally, the voting outcome is indeterminate for any no-debtequilibrium, since both parents and children are indifferent with regard to the repayment rate. Nevertheless, any voting outcome yields the same equilibrium payoffs.

Turning to debt-equilibria, we now investigate when and how parents manage to resolve the coordination problem and distribute in their favor. The corresponding equilibrium strategies depend on the size of the haircut that is available. Two cases must be distinguished: First, if a sufficiently large haircut is possible $\left(\underline{\theta}<\left(1-\gamma_{p}\right) /\left(\alpha_{p} r\right)\right)$, parents prefer to invest in government bonds if and only if the high repayment rate is selected. A failure to coordinate would thus result in losses compared to a world where government bonds are not available, and fear of coordination failure may lead parents to abstain from investing. On the other hand if only a small haircut is implementable $\left(\underline{\theta}>\left(1-\gamma_{p}\right) /\left(\alpha_{p} r\right)\right)$, parents prefer to invest regardless of the voting outcome. Still, not investing the complete endowment may be beneficial since it induces the high repayment rate. Therefore, a free rider problem arises since every player prefers not to forgo positive investment returns.

Denote by $\hat{G}(\cdot)$ the empirical wealth distribution, i.e. the distribution of realized wealth levels $e_{i}$ drawn independently from $G(\cdot)$, and let $\bar{e}=\int_{\mathbb{R}_{+}} e d \hat{G}(e)$. 
Proposition 3. Let $\underline{\theta}<\frac{1-\gamma_{p}}{\alpha_{p} r}<\bar{\theta}$.

(a) A debt-equilibrium satisfies $\theta^{*}=\bar{\theta}$ and exists if and only if $\alpha_{c}>\left\lceil\frac{1}{2} \frac{n-1}{n} I\right\rceil / I$.

(b) If $\hat{G}\left(\frac{\bar{e}}{\alpha_{c}}\right)<\frac{1}{2} \frac{n+1}{n}$, there exists a debt-equilibrium with $s_{i}^{*}=e_{i}$ for each $i=1, \ldots, I$. It is the unique debt-equilibrium if and only if (additionally) $\alpha_{c}>1 / I$ and $n(I-2)<I$.

(c) If $\hat{G}\left(\frac{\bar{e}}{\alpha_{c}}\right)>\frac{1}{2} \frac{n+1}{n}$, multiple debt-equilibria exist. Any debt-equilibrium satisfies (i) $s_{i}^{*}<e_{i}$ for some $i \in\{1, \ldots, I\}$, (ii) $\min _{i} s_{i}^{*}<\max _{i} s_{i}^{*}$, (iii) $H\left(\frac{\bar{s}^{*}}{\alpha_{c}}+\frac{d}{\alpha_{c} I}\right)-H\left(\frac{\bar{s}^{*}}{\alpha_{c}}\right)>0$, and (iv) $1-H\left(\frac{\bar{s}^{*}}{\alpha_{c}}+\frac{d}{\alpha_{c} I}\right)<\frac{1}{2} \frac{n-1}{n}$.

The proposition delivers three messages. First, it establishes that coordinating intergenerational redistribution is only possible if children benefit sufficiently from their parent's investment (part a). Second, it identifies conditions that favor coordination and therefore intergenerational redistribution (part b). Coordination is easily achieved if the (empirical) wealth distribution satisfies condition (1). ${ }^{7}$ In this case, every parent can fully invest into government bonds and still ensure the high repayment rate. Accordingly, the maximum amount of debt is issued in this equilibrium. The likelihood of the latter depends on the rate of population growth. Coordination takes place with probability one, if it suffices that a single kid supports the old, i.e. if population growth is close to zero $(n<I /(I-2))$. Otherwise, other and from the parents' perspective less favorable equilibria exist which are, however, also less salient. Finally, the proposition shows how coordination is also possible if the wealth distribution is unfavorable (part c). Coordinating intergenerational redistribution requires some parents to hold back and not invest their entire endowment. In particular, investments must be unequal, some parents' investments must be close to the threshold $\bar{s} / \alpha_{c}$ (inducing moderately wealthy heirs), and these investments are decisive in the sense that the very wealthy are not sufficient to guarantee a high repayment rate.

We finally turn to the case where only a small fraction of government debt may be repudiated. In this case, government debt is issued in any equilibrium. We therefore focus on the question how the threat to lose part of the investment constrains the old generation's demand for debt.

Proposition 4. Let $\underline{\theta}>\frac{1-\gamma_{p}}{\alpha_{p} r}$ such that only debt-equilibria exist.

(a) If $\hat{G}\left(\frac{\bar{e}}{\alpha_{c}}\right)<\frac{1}{2} \frac{n+1}{n}$, there exists an equilibrium with $s_{i}^{*}=e_{i}$ for each $i=1, \ldots, I$, and each equilibrium satisfies $\theta^{*}=\bar{\theta}$.

(b) Any equilibrium with $\theta^{*}=\bar{\theta}$ satisfies for each $i=1, \ldots, I$

$$
\frac{s_{i}}{e_{i}}>\frac{\alpha_{p} r \underline{\theta}-\left(1-\gamma_{p}\right)}{\alpha_{p} r \bar{\theta}-\left(1-\gamma_{p}\right)} .
$$

${ }^{7}$ As the number of families, $I$, grows large the condition is put on the actual distribution of endowments. 
(c) If $\hat{G}\left(\frac{\bar{e}}{\alpha_{c}}\right)>\frac{1}{2} \frac{n+1}{n}$, an equilibrium with $\theta^{*}=\bar{\theta}$ exists if

$$
\max _{i} e_{i}>\left[I \bar{e}-I \alpha_{c} \hat{G}^{-1}\left(\frac{1}{2} \frac{n+1}{n}\right)\right] \frac{\alpha_{p} r(\bar{\theta}-\underline{\theta})}{\alpha_{p} r \bar{\theta}-\left(1-\gamma_{p}\right)} .
$$

for sufficiently small $d .^{8}$ Otherwise, an equilibrium with $\theta^{*}=\underline{\theta}$ exists and satisfies $s_{i}^{*}=e_{i}$ for each $i=1, \ldots, I$.

As before, if the wealth distribution satisfies condition (1), coordination is easiest and the maximum amount of debt may be issued in equilibrium (part a). We focus on the case where this equilibrium is not available and we investigate when and how parents manage to coordinate full repayment of the debt. ${ }^{9}$ A necessary condition for full repayment is that all parents invest a minimum fraction of their endowment (part b). Otherwise, low investors have an incentive to deviate by investing everything. Part (c) in turn provides a sufficient condition for full repayment - a wealth distribution that features some very rich individuals. Such individuals can unilaterally induce full repayment by not investing their entire wealth. A large wealth implies that this deviation is also profitable since returns on the remaining investment are still sufficiently high. As the minimum wealth level of those super-rich individuals (the RHS of (2)) is smaller, the larger the fraction of wealthy parents (the larger $\hat{G}^{-1}\left(\frac{1}{2} \frac{n+1}{n}\right)$ ), full repayment is also favored by a higher top wealth share.

\subsection{Discussion: Inequality, Government Debt, and Coordination}

How does wealth inequality affect accumulation and repayment of government debt? Similar to Tabellini (1991), we show that debt may be held neither too widely nor too narrowly to make repayment politically viable. This suggests that a similar property must hold for the initial wealth distribution. However, contrary to Tabellini (1991), our model identifies coordination as an important factor of intergenerational redistribution. First, multiple equilibria often exist even if the wealth distribution favors repayment of debt (Proposition 3b and 4a). Accordingly, coordination is necessary to achieve intergenerational redistribution. Second, coordination enables intergenerational redistribution even if the wealth distribution is unfavorable towards debt repayment. Coordination therefore mediates the impact of wealth inequality on the budget deficit.

Still, the wealth distribution may facilitate coordination. In particular, if wealth inequality is neither too small nor too large (i.e. satisfies condition 1), simple strategic behavior (each parent invests her entire wealth, or a constant fraction thereof) leads to the issuance of the largest amount of debt and guarantees its repayment. Can we expect the wealth distribution to have this property? The answer to this question very much

\footnotetext{
${ }^{8}$ For general grid size $d$, the condition is $d \cdot\left\lceil\frac{\alpha_{p} r \underline{\theta}-\left(1-\gamma_{p}\right)}{\alpha_{p} r \overline{\bar{\theta}}-\left(1-\gamma_{p}\right)} \frac{e_{i}}{d}\right\rceil>e_{i}-\left[I \bar{e}-I \alpha_{c} \hat{G}^{-1}\left(\frac{1}{2} \frac{n+1}{n}\right)\right]$ for each $i=1, \ldots, I$.
}

${ }^{9}$ In other words, we assume that $\bar{\theta}=1$ to facilitate the discussion. 
depends on the rate of population growth. If population growth is large, the properties are unlikely to be satisfied by the distribution of wealth, since most wealth distributions are skewed to the right (see e.g. Benhabib and Bisin, 2016). If population growth is small, a much higher top wealth share is politically viable. This offers another compelling reason why declining population growth may foster the accumulation of government debt.

Even if the wealth distribution does not satisfy condition (1), it affects coordination. Consider the very likely scenario that only a small fraction of the debt may be repudiated. In this case, the haircut is not invoked if the wealth distribution features some very rich individuals, and it is less likely the larger the top wealth share (see Proposition 4 and the discussion below).

The question how wealth inequality fosters the repayment of government debt is ultimately an empirical one. Yet, to the best of our knowledge, the only empirical study which addresses the relationship between government debt and inequality is Larch (2012). Moreover, this study focuses on inequality of income. Our model has the potential to inform further studies in this direction. In particular, we provide clear, testable predictions regarding the properties of the wealth distribution that favor the repayment of debt. Additionally, comparing the properties of the wealth distribution with those of the distribution of bond investments may provide insights into the resolution of the coordination problem. Still, any empirical study must resolve problems of measurement and reverse causality. Those studies should therefore be complemented by experimental analyses. In the next section, we present a first attempt to study the strategic use of inter- and intragenerational redistribution experimentally.

Finally, our model also provides some guidance regarding stabilizing factors that prevent an excessive accumulation of debt. First, as already discussed, a larger population growth and lower wealth inequality (especially if population growth is small) constrain the amount of debt that may be issued. Second, the possibility to invoke a haircut may also constrain the amount of debt, or prevent issuance altogether. Third, boundaries on inheritance weaken the connection between old and young and therefore complicate the use of the divide-and-conquer mechanism. Each of these factors has the potential to hamper coordination within the old generation. At best, even small changes can have large impact, if they cause coordination to break down. 


\section{Experimental Evidence}

To shed more light on the relevance of the redistributive mechanism we conduct an experimental test of our simple game-theoretic model. This approach enables us to study behavior under controlled, ceteris paribus conditions and therefore to avoid problems of measurement and reverse causality that abound in field studies (cf. Sutter, 2003). We are interested, in particular, in the resolution of the coordination problem under two scenarios: when the distribution of wealth is favorable and when it is not. To focus on this issue, we frame the experiment in neutral terms and we avoid any reference to public debt, which might evoke specific associations in our subjects.

\subsection{Design and Procedures}

We are interested in the coordination of redistribution in the simplest possible environment. We therefore test versions of the model in which $I=n=2$. Accordingly, no-debtequilibria do not exist as any single parent can evoke the high repayment rate by investing a positive amount. Furthermore, we let $\gamma_{p}=\gamma_{c}=0$ in order to abstract from the public good aspect of the game.

The experiment closely follows the model developed in the previous section. Subjects are randomly assigned to groups of six which are fixed throughout a session. Each group plays 20 repetitions of the game which proceed as follows: At the beginning of a repetition, each subject learns about her endowment. Endowments are randomly assigned to subjects, in case they differ within a group (see below). All six subjects then simultaneously decide about their investment into government debt. ${ }^{10}$ After all investment decisions have been submitted, two subjects are randomly selected as parents (called investors) and each parent is randomly assigned two children (called partners). Only the investment decisions of parents are payoff-relevant. Given parents' investments, subjects vote on the repayment rate $\theta \in\{0,1\}$, and the high repayment rate $\bar{\theta}=1$ is selected if at least 4 out of 6 votes support it. At the end of the experiment, one repetition each out of the first and the last ten repetitions is randomly selected to determine subjects' earnings (including a show-upfee of $4 €)$.

To investigate the impact of inequality on coordination we implement two treatments named, respectively, treatment Symmetric and treatment Asymmetric. The treatments differ with respect to the distribution of endowments within a group. In treatment Symmetric, each subject receives an endowment of $5 €$ in each repetition. In treatment Asymmetric, half the subjects in a group are endowed with $6 €$, the other half are endowed with $4 €$, and exactly one subject with the high and one subject with the low endowment is selected as a parent in each repetition. Moreover, each parent is randomly assigned one child each with the low and the high endowment. Our design implies that the endowments of the children are also unequal in treatment Asymmetric. To maintain a basic feature

\footnotetext{
${ }^{10}$ Investments are multiples of 10 cents.
} 


\begin{tabular}{lccc}
\hline \hline Treatment & Symmetric & Asymmetric & Redistribution \\
\hline Endowments & $e_{1}=e_{2}=5 €$ & $e_{1}=6 €, e_{2}=4 €$ & $e_{1}=6 €, e_{2}=4 €$ \\
& $w_{i j} \equiv w=5 €$ & $w_{i 1}=6 €, w_{i 2}=4 €$ & $w_{i 1}=6 €, w_{i 2}=4 €$ \\
Parents' Payoffs & & & \\
if $\theta=0$ & $e_{i}-s_{i}$ & $e_{i}-s_{i}$ & $e_{i}$ \\
if $\theta=1$ & $e_{i}+s_{i}$ & $e_{i}+s_{i}$ & $e_{i}+0.4 s_{i}$ \\
Children's Payoffs & & & $w_{i j}$ \\
if $\theta=0$ & $w_{i j}$ & $w_{i j}$ & $w_{i j}+0.5 s_{i}-0.7 s_{-i}$ \\
if $\theta=1$ & $w_{i j}+0.4 s_{i}-0.5 s_{-i}$ & $w_{i j}+0.4 s_{i}-0.5 s_{-i}$ & \\
Equilibrium Investments & $s_{1}^{*}=5 €$ & $s_{1}^{*}=6 €$ & $s_{1}^{*}=6 €$ \\
Parent 1 & $s_{2}^{*} \in\{3.9 €, 4 €\}$ & $s_{2}^{*}=4 €$ & $s_{2}^{*}=4 €$ \\
Parent 2
\end{tabular}

Table 1:Summary of the Treatments and Equilibria

of the model and keep treatments comparable, we assume that each child bears the same tax burden $r \cdot \sum_{i} s_{i} / 4$ in case the repayment rate $\theta=\bar{\theta}=1$ is selected. The remaining parameters of the game are selected in order to maximize incentives to coordinate. They are given by $r=2, \alpha_{p}=1$, and $\alpha_{c}=0.9$.

One potential concern with the experimental design is the fact that repudiating the investments (selecting the low repayment rate $\theta=\underline{\theta}=0$ ) decreases overall welfare. ${ }^{11}$ Subjects with efficiency concerns (see e.g. Engelmann and Strobel, 2004) might therefore vote against their self-interest and facilitate redistribution. To investigate the influence of social preferences, we conduct a third treatment - Redistribution - which is a variation of treatment Asymmetric. The main difference is that investments are fully refunded in treatment Redistribution, if the low repayment rate is selected by the (weak) majority (i.e. $\left.\pi_{i}(s, \underline{\theta})=e_{i}\right)$. Accordingly, group welfare remains constant regardless of the voting outcome. ${ }^{12}$ The remaining parameters $r=2.8, \alpha_{p}=0.5$, and $\alpha_{c}=6 / 7$ have been selected to minimize the support for intergenerational redistribution. In particular, the potential gain of the parents and of those children supporting redistribution is smallest, and the potential loss of the children opposing redistribution is largest in this treatment. The treatment therefore constitutes a stress test of the redistributive mechanism's robustness against factors such as fairness not taken into account in the model.

Table 1 summarizes the different treatments and their equilibria. In treatments Asymmetric and Redistribution, a unique equilibrium exists in which subjects invest their entire endowment and the high repayment rate $\bar{\theta}=1$ is selected. In treatment Symmetric, there are multiple equilibria given by $s_{i}=e_{i}=5 €$ and $s_{j} \in\{3.90 €, 4.00 €\}$ for $i \neq j$.

Two sessions were conducted for each treatment. The sessions took place at the experi-

\footnotetext{
${ }^{11}$ Straightforward calculations imply that $\sum_{i}\left[\pi_{i}\left(\boldsymbol{s}, \boldsymbol{\theta}_{p}, \boldsymbol{\theta}_{c}\right)+\sum_{j} \pi_{i j}\left(\boldsymbol{s}, \boldsymbol{\theta}_{p}, \boldsymbol{\theta}_{c}\right)\right]=\sum_{i} e_{i}+$ Inw + $\left(I \gamma_{p}+I n \gamma_{c}-1\right) \sum_{i} s_{i}+\theta r\left(\alpha_{p}+\alpha_{c}-1\right) \sum_{i} s_{i}$ which is increasing in $\theta$ if $\alpha_{p}+\alpha_{c}>1$.

${ }^{12} \sum_{i}\left[\pi_{i}(s, \theta)+\sum_{j} \pi_{i j}(s, \theta)\right]=30 €$ for each $s$ and each $\theta \in\{0,1\}$.
} 


\begin{tabular}{lccccc}
\hline \hline & \multicolumn{5}{c}{ Treatment } \\
Player Type & Symmetric & & Asymmetric & & Redistribution \\
\hline Parents & $99.3 \%$ & $\sim$ & $97.5 \%$ & $\gtrsim$ & $94.6 \%$ \\
Children with $\underline{\theta} \geq \bar{\theta}$ & $87.1 \%$ & $<$ & $94.7 \%$ & $>$ & $80.0 \%$ \\
Children with $\underline{\theta}<\bar{\theta}$ & $76.0 \%$ & $<$ & $87.1 \%$ & $\sim$ & $91.0 \%$ \\
\hline \hline
\end{tabular}

Note: Treatment comparisons are based on $\chi^{2}$-tests. $<(\succsim)$ indicates significance at the $1 \%$ (10\%) level.

\section{Table 2:Frequencies of Truthful Voting}

mental laboratory of the Technical University of Munich ("experimenTUM") in July 2015. Students from TU Munich were invited using the ORSEE recruitment system (Greiner, 2015). 24 subjects participated in each session.

Upon arrival at the lab, subjects were randomly assigned to cubicles that did not allow for any visual communication between them. Once all subjects were seated, paper instructions were distributed and subjects were given time to read them at their own pace. Instructions were then read aloud and subjects were permitted to ask questions. All decisions were submitted through computer terminals using an interface programmed in zTree (Fischbacher, 2007). The interface also provided tools to assist subjects in their decisionmaking. In particular, before choosing their investment, subjects had the opportunity to enter fictitious investments for themselves and the other investor to learn about the resulting earnings of each group member under the two possible voting outcomes. Similarly, before voting, subjects where shown the earnings of all six group members (anonymized) for each possible voting outcome. At the end of the 20 rounds, ${ }^{13}$ subjects filled out a short questionnaire consisting of some demographic questions and some questions related to the experiment. Afterwards, they retrieved their earnings in private and left.

Sessions lasted 75 minutes on average. The average payment was $13.60 €$ in treatment Symmetric, $15.20 €$ in treatment Asymmetric, and $14.20 €$ in treatment Redistribution. Overall, we collected 2,712 investment and voting decisions submitted by 144 subjects.

\subsection{Results}

We discuss the experimental results in three steps. We first discuss subjects' voting behavior. Second, we analyze subjects' investment decisions. Finally, we combine the results to address the effectiveness of redistribution.

\subsubsection{Voting}

Table 2 presents average frequencies of truthful voting for the different treatments and different types of players. The numbers exclude voting decisions in which a subject was tied between the two options. We note first that across treatments and player types, a

\footnotetext{
${ }^{13}$ Due to time constraints one session in treatment Asymmetric had to be stopped after round 13.
} 
large majority of subjects vote truthfully. Still, differences between the treatments and the types of players exist. In particular, compared to treatment Asymmetric, children vote significantly less truthfully in treatment Symmetric which further hinders redistribution in the latter treatment. Furthermore, parents and children supporting redistribution vote more truthfully in treatment Asymmetric than in treatment Redistribution. Though this result seems to indicate the presence of efficiency concerns, note that average frequencies do not account for differences in the incentives to vote truthfully. Indeed, the average difference between the payoffs of a truthful and an untruthful vote in treatment Asymmetric, Symmetric, and Redistribution, respectively, is $7.78 €, 7.03 €$, and $1.80 €$ for parents, $0.85 €, 0.73 €$, and $0.62 €$ for children supporting redistribution, and $1.36 €, 0.81 €$, and $1.93 €$ for children opposed to redistribution. These differences also complicate comparisons across types of players.

To take into account the different incentives subjects face, we estimate a logit model of the decision to vote truthfully. The model includes as explanatory variables the payoff difference between the more and the less preferred option, treatment dummies, dummies for the different player types, and interactions between those dummies, and it allows for subject-specific random effects. In alternative specifications, we also incorporate a period trend and demographic controls. ${ }^{14}$ The results are presented in table B1 in Appendix B. We find a strong incentive effect, as the coefficient of the difference in payoffs is always positive and highly significant. Averaging across observations where the payoff advantage of a truthful vote is at least $1.00 €$, the frequency of truthful votes is larger than 90 percent for each treatment and each player type. Second, we find that controlling for incentives alleviates the differences between treatments. In particular, the only difference in voting behavior between treatments Symmetric and Asymmetric occurs for children supporting redistribution which are less inclined to vote truthfully in treatment Symmetric. Furthermore, compared to treatment Asymmetric, parents vote more truthfully but children supporting redistribution vote less truthfully in treatment Redistribution. We therefore obtain mixed results regarding subjects' concerns for efficiency. Finally, we find that, holding incentives constant, children supporting redistribution are more inclined to vote truthfully than both parents and children opposed to redistribution in treatment Asymmetric.

The following result summarizes our findings for the voting stage.

Result 1. A large majority of subjects vote truthfully and they are more inclined to do so the larger the incentives. Differences between treatments and player types are not systematic.

\footnotetext{
${ }^{14}$ Concretely, we control for age, gender, academic major, high-school graduation grade, mother tongue, and self-assessments on risk-aversion, egoism, generosity, and ambition.
} 


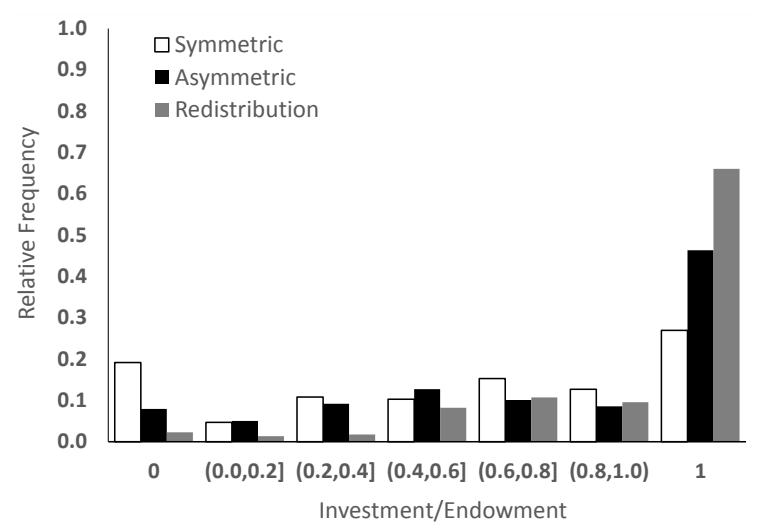

(A) Frequency Distribution

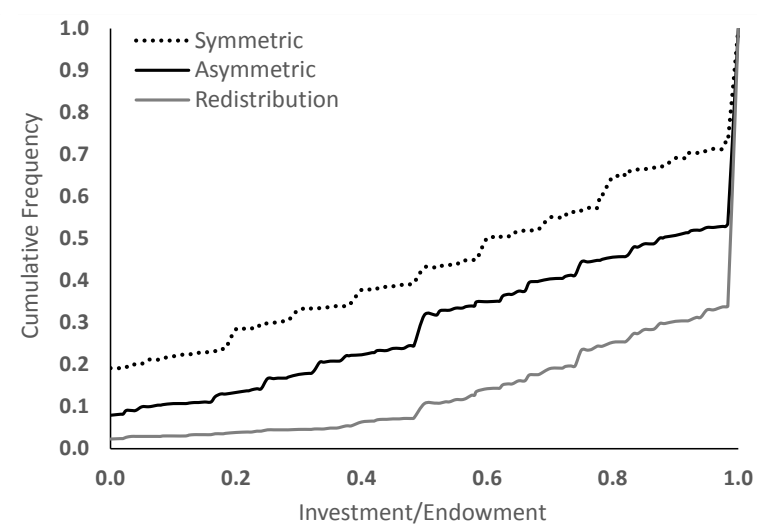

(B) Cumulative Distribution

Figure 2:Distribution of (Relative) Investments by Treatment

\subsubsection{Investment Decisions}

Figure 2 displays the distribution of investments as a fraction of the endowment for the different treatments. The left (right) panel depicts the (cumulative) frequency distribution. The figures reveal that investments are lowest in treatment Symmetric and highest in treatment Redistribution. For example, the average investment equals $3.56 €$ in treatment Asymmetric, $2.83 €$ in treatment Symmetric, and $4.36 €$ in treatment Redistribution. These differences are significant at any conventional level both using a one-sided $t$-test for equality of the average (absolute or relative) investment and a Kolmogorov-Smirnov test for equality of distributions (of the relative investments). ${ }^{15}$ In addition, we find that the standard deviation of relative investments is lowest in treatment Redistribution $(\sigma=0.24)$, moderate in treatment Asymmetric $(\sigma=0.35)$ and highest in treatment Symmetric $(\sigma=0.39)$. Again, the differences are significant at the $1 \%$-level using an F-test for equality of variances.

The results suggest that subjects recognize the incentives to coordinate with both heterogeneous and homogeneous endowments. In treatments Asymmetric and Redistribution, subjects frequently invest their entire endowment (in $46 \%$ and $66 \%$ of all decisions, respectively). Moreover, investments increase over time in treatment Asymmetric (the average investment equals, respectively, $3.41 €$ and $3.80 €$ across the first and the last ten periods) suggesting that subjects adapt towards the unique equilibrium. Finally, the difference between the two treatments indicates that deviations from equilibrium investments are partially explained by risk (or loss) aversion, as subjects cannot earn less than their endowment in treatment Redistribution (see also the regression results discussed below).

In contrast, subjects invest on average substantially less than their endowment in treatment Symmetric, and they rarely invest their entire endowment (27\% of all decisions). Moreover, investments are widely dispersed. Both properties may be interpreted as an attempt to achieve coordination in a difficult environment.

\footnotetext{
${ }^{15}$ The results are robust to the exclusion of investments equal to zero.
} 
Result 2. Subjects select investments to coordinate redistribution. In particular, subjects frequently invest their entire endowment, if endowments are heterogeneous, whereas investments are substantially lower and more dispersed with homogeneous endowments.

To better understand what drives investment behavior, we estimate linear regression and Tobit models of the relative investment, i.e. the fraction of the endowment invested into government bonds. ${ }^{16}$ The models allow for subject-specific random-effects, and they contain as explanatory variables a dummy for the high endowment (for treatments Asymmetric and Redistribution), a period trend, and several demographics and other responses to our final questionnaire. ${ }^{17}$ Tables B2 and B3 in Appendix B contain the estimation results.

We note first that few of the explanatory variables have a significant impact in treatment Symmetric. This again indicates the complicated nature of the coordination task in this treatment. In contrast, we find several effects for the other two treatments. First, subjects with a better high-school grade and subjects whose mother tongue is German invest more. Both effects are re-assuring since they suggest that a better understanding of the instructions increases the likelihood of equilibrium behavior. Second, we find that a subject's willingness to take risks is positively related to the size of her investment in treatment Asymmetric but not in treatment Redistribution. This corroborates our interpretation of the differences between the two treatments. Third, subjects who state taking the sum of payoffs into account in their voting decision invest more in treatment Asymmmetric while this has no effect in treatment Redistribution (where the sum of payoffs is independent of the investment and voting decisions). In addition, subjects who care for their partners' payoffs in their voting decision invest significantly less (more) in treatment Asymmetric (Redistribution). These findings imply that subjects' other-regarding preferences influence their investment decision.

In summary, in treatments with a unique equilibrium, subjects' investment decisions are systematically influenced by subjects' understanding, risk aversion, and other-regarding preferences.

\footnotetext{
${ }^{16}$ Results for absolute investments are similar and available from the authors upon request.

${ }^{17}$ Specifically, we include (i) age, gender, academic major, high-school grade, and mother tongue; (ii) self-assessments on risk-aversion, egoism, gift-giving, generosity, ambition, and the importance attached to own earnings and creating a majority; and (iii) dummy variables for stated motives for the voting decision where subjects were able to choose several among 5 possibilities: "maximizing own payoff", "maximizing the sum of payoffs in the group", "maximizing the payoff of the partner(s)", "achieving a (nearly) equal distribution of payoffs in the group", or "I always rejected".
} 


\begin{tabular}{lccc}
\hline \hline Treatment & Symmetric & Asymmetric & Redistribution \\
\hline Number of Proposals & 160 & 132 & 160 \\
\hline Proposals Favoring Repayment & $59(36.9 \%)$ & $100(75.8 \%)$ & $124(77.5 \%)$ \\
among: Majority for Repayment & $45(76.3 \%)$ & $87(87.0 \%)$ & $75(60.5 \%)$ \\
Majority for Repudiation & $14(23.7 \%)$ & $13(13.0 \%)$ & $49(39.5 \%)$ \\
\hline Proposals Favoring Repudiation & $101(63.1 \%)$ & $32(24.2 \%)$ & $36(22.5 \%)$ \\
among: Majority for Repayment & $43(42.6 \%)$ & $13(40.6 \%)$ & $6(16.7 \%)$ \\
$\quad$ Majority for Repudiation & $58(57.4 \%)$ & $19(59.4 \%)$ & $30(83.3 \%)$ \\
\hline \hline
\end{tabular}

Table 3:The Success of Coordination and Redistribution

\subsubsection{The Success of Coordination and Redistribution}

We finally examine the success of parents in coordinating and redistributing in their favor. Table 3 summarizes the number of proposals $s=\left(s_{1}, s_{2}\right)$ which would lead to repayment or repudiation, if subjects voted truthfully. The table also summarizes the actual voting outcomes in each case.

In treatments Asymmetric and Redistribution, a large majority of proposals resulted in a majority favoring repayment. In treatment Asymmetric, voting also resulted in repayment in most of these cases such that overall, subjects managed to coordinate redistribution in $65.9 \%$ of game plays. As investments were accepted in 13 additional cases in which truthful voting would have led to repudiation, $75.8 \%$ of game plays involved redistribution in favor of parents. The high frequency of successful redistribution results in a substantial payoff inequality in treatment Asymmetric. On average, parents (children) attained a payoff equal to $7.07 €(4.72 €)$. In contrast, only 81 out of 160 proposals were accepted in treatment Redistribution. This owes to the lower propensities of truthful voting. Indeed, 124 proposals would have led to repayment under truthful voting. Overall, parents (children) attained an average payoff equal to $5.91 €(4.55 €)$ in treatment Redistribution.

Frequencies of successful coordination are lower in treatment Symmetric. Investors managed to coordinate a majority in favor of redistribution in only 59 out of 160 game plays. Ultimately, 45 of these proposals were accepted. Notice however that due to our experimental design, coordination is harder to achieve in this treatment. For instance, if exactly half the players in each group were to choose each the low and the high equilibrium investment, the expected frequency of coordinated proposals would be merely $50 \%$. A uniform distribution of investments yields an expected frequency of coordination as high as $80 \%$. Accordingly, subjects were quite successful in coordinating redistribution in treatment Symmetric, though less than under the more favorable conditions in the other treatments. Indeed, average payoffs for parents $(5.56 €)$ and children $(4.83 €)$ reveal that redistribution took place to some extent even under unfavorable conditions.

Result 3. Subjects achieve debt repayment both if this is favored by the initial wealth distribution, and if it is not. Hence, coordination is the driving force of debt repayment. 


\section{Conclusion}

How does the link between inter- and intragenerational redistribution foster the repayment and, in turn, the accumulation of government debt? We identify a strategic component of Tabellini's (1991) redistributive mechanism that has largely been neglected in previous work on this topic. By successfully coordinating their bond investments, parents can exploit a link between inter- and intragenerational redistribution even if the wealth distribution does not favor debt repayment, i.e. features too much or too little inequality. Moreover, multiple equilibria often exist even if the wealth distribution favors the repayment of debt. Our model therefore shows that coordination mediates the impact of wealth inequality on the budget deficit. In addition, the model sheds light on other factors of debt accumulation. In particular, declining population growth and bounds on inheritance limit debt accumulation. Since coordination also mediates the impact of those factors, small changes can have large impact if they cause coordination to break down.

Our model enables us to experimentally test Tabellini's (1991) redistributive mechanism. The experimental results corroborate our model implications. In particular, subjects manage to coordinate the repayment of debt in more than one-third of game plays if wealth inequality is absent and the wealth distribution therefore does not favor debt repayment. They do so despite the multiplicity of equilibria and the complications introduced by our experimental design. Further studies should dig deeper into this finding by studying whether factors commonly found to foster coordination such as communication further increase the frequency of coordinated redistribution.

Finally, our paper highlights that parents employ a divide-and-conquer strategy towards the young generation. By generating a politically viable distribution of debt, parents manage to form a coalition with some of the children to redistribute from young to old. This connects the paper to a wide literature in political-economics and makes some of the findings in that literature applicable to fiscal policy questions. For example, Weingast $(1995,1997)$ argues that constitutional regulations are only effective to the extent that they are accepted as a consensus by the general public. This sheds a new light on constitutional constraints regarding the budget deficit. For example, the Stability and Growth Pact of the European Monetary Union may have been frequently violated exactly because the majority of citizens did not understand its importance and was not willing to defend it in the face of transgressions against it. In turn, recently introduced constitutional debt ceilings such as the German debt brake may prove all the more effective since they originated in an economic crisis that "dislodge[d] the old pattern" (Weingast, 1997, p.258).

Besides fiscal policy, there are several other avenues for future research. In particular, we extend the theoretical and experimental literature on divide-and-conquer by adding coordination as a prerequisite. This plays a role e.g. in subcommittee legislation in the U.S. (see Eavey and Miller, 1995) and might be an interesting extensions of existing studies (e.g. Cason and Mui, 2007, 2014, 2015). 


\section{Appendix A. Proofs}

Proof of Lemma 1. Children ex ante prefer the low repayment rate if and only if overall welfare of children is decreasing in $\theta$. Given investment profile $s$ and repayment rate $\theta$ selected by the majority, the welfare of children is given by

$$
\pi_{c}(s, \theta)=\sum_{i=1}^{I} \sum_{j=1}^{n} \pi_{i, j}(s, \theta)=\operatorname{In} w+\gamma_{c} \operatorname{In} \sum_{i=1}^{I} s_{i}+\theta r\left(\alpha_{c}-1\right) \sum_{i=1}^{I} s_{i} .
$$

Accordingly, $\partial \pi_{c}(s, \theta) / \partial \theta<0$ if and only if $\alpha_{c}<1$.

Proof of Proposition 2. Parent $i$ invests in government bonds, if the net return from investing is positive. Let $\theta$ denote the anticipated repayment rate selected in period 2 . Parent $i$ 's payoff is then given by

$$
\pi_{i}(s, \theta)=e_{i}+\gamma_{p} \sum_{j \neq i} s_{j}+s_{i}\left[\gamma_{p}+\alpha_{p} \theta r-1\right] .
$$

Accordingly, $\pi_{i}$ is increasing in $s_{i}$ provided $\gamma_{p}+\alpha_{p} \theta r>1$, or equivalently

$$
\theta>\frac{1-\gamma_{p}}{\alpha_{p} r}
$$

Therefore, investing nothing cannot be optimal, if $\frac{1-\gamma_{p}}{\alpha_{p} r}<\underline{\theta}<\bar{\theta}$, and investing a positive amount cannot be optimal, if $\underline{\theta}<\bar{\theta}<\frac{1-\gamma_{p}}{\alpha_{p} r}$.

Consider the case $\underline{\theta}<\frac{1-\gamma_{p}}{\alpha_{p} r}<\bar{\theta}$. The investment profile $\boldsymbol{s}_{0}^{*}=(0, \ldots, 0)$ is an equilibrium, if no parent is able to benefit from investing a positive amount. Assume that parent $i$ deviates from $s_{0}^{\star}$ by investing $s_{i}>0$. It follows that $\bar{s}=s_{i} / I$. Therefore, parent $i$ 's children are induced to vote for the high repayment rate if and only if $\alpha_{c}>1 / I$. Furthermore, this vote suffices to form a majority with the old if and only if $\frac{I+n}{I+n I}>\frac{1}{2}$, or equivalently $n \cdot(I-2)<I$. If either of the two conditions is violated, i.e. $\alpha_{c}<1 / I$ or $n \cdot(I-$ $2)>I$, a unilateral deviation from $s_{0}^{*}$ is not profitable. Finally, uniqueness follows from Proposition 3 .

Proof of Proposition 3. Ad (a): Since $\underline{\theta}<\frac{1-\gamma_{p}}{\alpha_{p} r}$, investing a positive amount is not a best response when the low repayment rate is selected. Hence, $\theta^{*}=\bar{\theta}$ in any debtequilibrium. Let

$$
J=\left\lceil\frac{1}{2} \frac{n-1}{n} I\right\rceil .
$$

We show that a debt equilibrium exists only if $\theta=\bar{\theta}$ is selected for the investment profile $\hat{s}^{*}$ given by $\hat{s}_{1}^{*}=\ldots=\hat{s}_{J}^{*}=\hat{s}^{*}$ for some $0<\hat{s}^{*} \leq \min _{i} e_{i}$ and $\hat{s}_{i}^{*}=0$ for $i>J$. To see this, consider any debt-equilibrium and assume without loss of generality that $s_{1}^{*} \geq s_{2}^{*} \geq \ldots \geq s_{I}^{*}$. Equilibrium implies that $\alpha_{c} s_{J}^{*}>\bar{s}^{*}$. Reducing $s_{1}, \ldots, s_{J-1}$ to $s_{J}^{*}$ and $s_{J+1}, \ldots, s_{I}$ to zero reduces $\bar{s}^{*}$ and does not affect the voting outcome. The latter is also true for a change of 
$s_{1}, \ldots, s_{J}$ to $\hat{s}^{*}$. It follows that a debt equilibrium exists only if $\alpha_{c} \hat{s}^{*}>\frac{J}{I} \hat{s}^{*}$ since otherwise the high repayment rate would not be selected given investment profile $\hat{\boldsymbol{s}}^{*}$. Conversely, if $\theta=\bar{\theta}$ given $s=\hat{\boldsymbol{s}}^{*}$, starting from the profile $\hat{\boldsymbol{s}}^{*}$ and increasing investments parent by parent until any further increase would imply $\theta=\underline{\theta}^{*}$ yields a debt-equilibrium.

Ad (b): Assume $\alpha_{c}>\frac{J}{I}$ and let $\boldsymbol{e}=\left(e_{1}, \ldots, e_{I}\right)$. First, $\boldsymbol{s}=\boldsymbol{e}$ implies that the empirical distribution of investments, $H$, coincides with $\hat{G}$. Accordingly, if $\hat{G}$ satisfies condition (1), so does $H$ and $\boldsymbol{e}$ is an equilibrium.

Second, a no-debt-equilibrium exists unless $\alpha_{c}>1 / I$ and $n \cdot(I-2)<I$ by Proposition 2 . Hence, the two conditions are necessary for uniqueness of the equilibrium $\boldsymbol{e}$. We show that they are also necessary and sufficient for the existence of a unique debt-equilibrium.

Necessity: Let $\underline{e}=\min _{i} e_{i}$ and $K=\left\lfloor\alpha_{c} I\right\rfloor=\max \left\{z \in \mathbb{Z}: z<\alpha_{c} I\right\}$ and consider the strategy profile $s^{\prime}$ given by (i) $s_{1}^{\prime}=\ldots=s_{K}^{\prime}=\underline{e}$, (ii) $s_{K+2}^{\prime}=\ldots=s_{I}^{\prime}=0$, and (iii) $s_{K+1}^{\prime}=\max \left\{s \in S_{K+1}: s<\left(\alpha_{c} I-K\right) \cdot \underline{e}\right\}$. It is easily seen that $\alpha_{c} \underline{e}-d / I<\bar{s}^{\prime}<\alpha_{c} \underline{e}$. Furthermore, $s_{K+1}<\underline{e}$ since $\alpha_{c} I-K<1$. Therefore, the children of parents $1, \ldots, K$ $(K+1, \ldots, I)$ vote for $\bar{\theta}(\underline{\theta})$. It follows from $\alpha_{c} I>\left\lceil\frac{1}{2} \frac{n-1}{n} I\right\rceil$ (a) that $K \geq J$ and therefore $\theta=\bar{\theta}$. Hence, no parent has an incentive to deviate from $s^{\prime}$ by investing less. Furthermore, investing more is not a profitable deviation from $s^{\prime}$ for some parent $i>K$ if $n \cdot(I-2)>I$. To see this consider a deviation to $s_{i} \geq s_{i}^{\prime}+d$. The new average investment satisfies $\bar{s}^{\prime}+\left(s_{i}-s_{i}^{\prime}\right) / I \geq \bar{s}^{\prime}+d / I>\alpha_{c} \underline{e}$ which implies that the children of parents $j=1, \ldots, K$ no longer vote for $\bar{\theta}$. Accordingly, only the children of parent $i$ vote for $\bar{\theta}$ after such a deviation and this cannot be profitable if $n \cdot(I-2)>I$. Hence, $\boldsymbol{e}$ is the unique debt-equilibrium only if $n \cdot(I-2)<I$ since otherwise $\boldsymbol{s}^{\prime}$ would constitute a debt-equilibrium as well.

Sufficiency: Assume $n \cdot(I-2)<I$ and, without loss of generality, $e_{1} \geq e_{2} \geq \ldots \geq e_{I}$. Consider a strategy profile $s \neq \boldsymbol{e}$ and let $\ell=\min \left\{i: s_{i}<e_{i}\right\}$. Clearly, $\bar{s}<\bar{s}+\left(e_{\ell}-s_{\ell}\right) / I \leq \bar{e}$. There are two cases:

$\alpha_{c} e_{\ell}>\bar{e}>\bar{s}+\left(e_{\ell}-s_{\ell}\right) / I$ implies that increasing $s_{\ell}$ to $e_{\ell}$ induces $\theta=\bar{\theta}$ because the children of parent $\ell$ vote for $\bar{\theta}$ and this suffices since $n \cdot(I-2)<I$. Hence, there exists a profitable deviation from $s$ if $\alpha_{c} e_{\ell}>\bar{e}$.

$\alpha_{c} e_{\ell}<\bar{e}$ implies that $s_{i}=e_{i}$ for $i<\ell$ by definition of $\ell$ and $\ell>J$ by the ordering of the $e_{i}$ and since $\boldsymbol{e}$ is assumed to be an equilibrium. Therefore, $\alpha_{c} s_{i}=\alpha_{c} e_{i}>\bar{e} \geq \bar{s}+\left(e_{\ell}-s_{\ell}\right) / I$ for $i=1, \ldots, J$ and increasing $s_{\ell}$ to $e_{\ell}$ is profitable since it does not change the voting outcome $\theta=\bar{\theta}$.

$A d(c)$ : Conditions (i) and (ii) are easily seen since $G\left(\frac{\bar{e}}{\alpha_{c}}\right)>\frac{1}{2} \frac{n+1}{n}$, and since $s_{1}=s_{2}=$ $\ldots=s_{I}=\bar{s}$ violates condition (1). For conditions (iii) and (iv), consider a strategy profile $s$, a parent $j$ such that $s_{j}<e_{j}$, and a deviation $s_{j}^{\prime}=s_{j}+d$ which implies $\bar{s}^{\prime}=\bar{s}+\frac{d}{I}$. The deviation may induce player $j$ 's kids to change their votes from $\underline{\theta}$ to $\bar{\theta}$ but not vice versa. On the other hand, the deviation induces the children of parents $i \neq j$ with $s_{i} \in\left[\frac{\bar{s}}{\alpha_{c}}, \frac{\bar{s}}{\alpha_{c}}+\frac{d}{I \alpha_{c}}\right]$ 
to switch votes from $\bar{\theta}$ to $\underline{\theta}$. If $s_{i} \notin\left[\frac{\bar{s}}{\alpha_{c}}, \frac{\bar{s}}{\alpha_{c}}+\frac{d}{I \alpha_{c}}\right]$ for each $i=1, \ldots, I$, this does not happen and the deviation is profitable. If $1-H\left(\frac{\bar{s}^{*}}{\alpha_{c}}+\frac{d}{\alpha_{c} I}\right)>\frac{1}{2} \frac{n-1}{n}$, the deviation leaves the majority in favor of the high repayment rate unaffected and is also profitable. In conclusion, $s$ is an equilibrium only if $s_{i} \in\left[\frac{\bar{s}}{\alpha_{c}}, \frac{\bar{s}}{\alpha_{c}}+\frac{d}{I \alpha_{c}}\right]$ for some $i \in\{1, \ldots, I\}$ and $1-H\left(\frac{\bar{s}^{*}}{\alpha_{c}}+\frac{d}{\alpha_{c} I}\right)<\frac{1}{2} \frac{n-1}{n}$.

To see multiplicity of debt-equilibria, assume first that $n(I-2)<I$. Hence, starting from $(0, \ldots, 0)$, any single parent $i$ can guarantee the high repayment rate by investing $s_{i}=e_{i}$. Increasing investments parent by parent for the remaining parents must stop at an equilibrium with $s_{j}^{*}<e_{j}$ for some $j \neq i$. Noting that $i$ was chosen arbitrarily finishes the proof for $n(I-2)<I$. Finally, the proof for $n(I-2)>I$ follows from the construction of the equilibrium $s^{\prime}$ as in (b) by noting that the assignment of $s_{i}=\underline{e}$ to parents $i \in\{1, \ldots, K\}$ (rather than any other subgroup of size $K$ ) is arbitrary.

Proof of Proposition 4. Ad (a): Since $\underline{\theta}>\frac{1-\gamma_{p}}{\alpha_{p} r}$, investing is profitable even if the low repayment rate is selected by the majority. Hence, there cannot exist an equilibrium such that $\theta^{*}=\underline{\theta}$ and $s_{i}^{*}<e_{i}$ for some $i \in\{1, \ldots, I\}$. Since $H$ coincides with $\hat{G}$ if $s=\boldsymbol{e}$, this strategy profile induces $\bar{\theta}$ if $\hat{G}$ satisfies condition (1), and therefore constitutes an equilibrium.

Ad (b): Let $\boldsymbol{s}^{*}$ denote an equilibrium with $\theta^{*}=\bar{\theta}$ and consider player $i$ such that $s_{i}^{*}<e_{i}{ }^{18}$ Deviating to $s_{i}=e_{i}$ must induce the low repayment rate for otherwise it would be a profitable deviation. Moreover, the payoff to player $i$ from investing $s_{i}=s_{i}^{*}$ when the repayment rate is high must be higher than the payoff from investing $s_{i}=e_{i}$ when the repayment rate is low:

$$
\begin{array}{cc} 
& e_{i}-s_{i}^{*}+\gamma_{p} \sum_{j=1}^{I} s_{j}^{*}+\alpha_{p} r \bar{\theta} s_{i}>\gamma_{p} \sum_{i=1}^{I} s_{i}^{*}+\gamma_{p}\left(e_{i}-s_{i}^{*}\right)+\alpha_{p} r \underline{\theta} e_{i} \\
\Leftrightarrow & \alpha_{p} r \bar{\theta} s_{i}^{*}-\left(1-\gamma_{p}\right) s_{i}^{*}>\alpha_{p} r \underline{\theta} e_{i}-\left(1-\gamma_{p}\right) e_{i} \\
\Leftrightarrow & \frac{s_{i}^{*}}{e_{i}}>\frac{\alpha_{p} r \underline{\theta}-\left(1-\gamma_{p}\right)}{\alpha_{p} r \bar{\theta}-\left(1-\gamma_{p}\right)} .
\end{array}
$$

$A d(c)$ : Consider the investment profile $s=e$ which induces $\theta^{*}=\underline{\theta}$. Player $i$ finds it profitable to deviate from $e$ if there exists $s_{i} \in S_{i}$ such that

$$
\begin{aligned}
& \text { (i) } \hat{G}\left(\frac{\bar{e}}{\alpha_{c}}-\frac{e_{i}-s_{i}}{I \alpha_{c}}\right)<\frac{1}{2} \frac{n+1}{n}, \\
& \text { (ii) } \frac{s_{i}}{e_{i}}>\frac{\alpha_{p} r \underline{\theta}-\left(1-\gamma_{p}\right)}{\alpha_{p} r \bar{\theta}-\left(1-\gamma_{p}\right)} .
\end{aligned}
$$

\footnotetext{
${ }^{18}$ If such a player does not exist, $s_{i} / e_{i}=1>\left[\alpha_{p} r \underline{\theta}-\left(1-\gamma_{p}\right)\right] /\left[\alpha_{p} r-\bar{\theta}-\left(1-\gamma_{p}\right)\right]$ for each $i=1, \ldots, I$ as requested.
} 
The first condition states that by selecting $s_{i}<e_{i}$ instead of $e_{i}$ and thus changing the average investment to $\bar{s}=\bar{e}-\left(e_{i}-s_{i}\right) / I$ the player can unilaterally induce $\bar{\theta}$. The second condition requires that this deviation is profitable as in (b). Condition (i) may be rewritten as

$$
\left(i^{\prime}\right) e_{i}-s_{i}>I\left[\bar{e}-\alpha_{c} \hat{G}^{-1}\left(\frac{1}{2}+\frac{1}{2 n}\right)\right] .
$$

Hence, a profitable deviation $s_{i}<e_{i}$ for player $i$ must satisfy

$$
\eta e_{i}<s_{i}<e_{i}-I\left[\bar{e}-\alpha_{c} \hat{G}^{-1}\left(\frac{1}{2} \frac{n+1}{n}\right)\right]
$$

where

$$
\eta \equiv \frac{\alpha_{p} r \underline{\theta}-\left(1-\gamma_{p}\right)}{\alpha_{p} r \bar{\theta}-\left(1-\gamma_{p}\right)}
$$

Such a deviation exists, if and only if

$$
d \cdot\left\lceil\frac{\eta e_{i}}{d}\right\rceil<e_{i}-I\left[\bar{e}-\alpha_{c} \hat{G}^{-1}\left(\frac{1}{2} \frac{n+1}{n}\right)\right] .
$$

For sufficiently small grid size $d$, this reduces to

$$
e_{i}>\frac{I\left[\bar{e}-\alpha_{c} \hat{G}^{-1}\left(\frac{1}{2} \frac{n+1}{n}\right)\right]}{1-\eta} .
$$

Accordingly, there exists a profitable deviation from $\boldsymbol{e}$ for some player $i$, if

$$
\max _{i} e_{i}>\frac{I\left[\bar{e}-\alpha_{c} \hat{G}^{-1}\left(\frac{1}{2} \frac{n+1}{n}\right)\right]}{1-\eta} .
$$

This condition is also sufficient for existence of an equilibrium $s^{*}$, since none of the parents can find it profitable to deviate from $s_{i}=e_{i}$ if the high repayment rate is selected in the voting.

Conversely, $\boldsymbol{e}$ is an equilibrium with $\theta^{*}=\underline{\theta}$ if and only if condition (2) does not hold, since this is equivalent to no player being able to unilaterally and profitably deviate from e. 


\section{Appendix B. Econometric Results}

\begin{tabular}{|c|c|c|c|}
\hline & \multicolumn{3}{|c|}{ Propensity to Vote Truthfully } \\
\hline & $(1)$ & $(2)$ & $(3)$ \\
\hline Constant & $\begin{array}{l}0.691 \\
(0.679)\end{array}$ & $\begin{array}{l}1.005 \\
(0.684)\end{array}$ & $\begin{array}{l}0.922 \\
(1.292)\end{array}$ \\
\hline Supporting Child & $\begin{array}{l}2.378^{* * *} \\
(0.696)\end{array}$ & $\begin{array}{l}2.665^{* * *} \\
(0.700)\end{array}$ & $\begin{array}{l}2.754^{* * *} \\
(0.705)\end{array}$ \\
\hline Opposed Child & $\begin{array}{l}0.902 \\
(0.621)\end{array}$ & $\begin{array}{l}1.111^{*} \\
(0.624)\end{array}$ & $\begin{array}{l}1.231^{*} \\
(0.629)\end{array}$ \\
\hline Symmetric & $\begin{array}{l}1.487 \\
(0.996)\end{array}$ & $\begin{array}{l}1.639 \\
(1.003)\end{array}$ & $\begin{array}{l}1.656 \\
(1.013)\end{array}$ \\
\hline × Supp. Child & $\begin{array}{l}-2.688^{* * *} \\
(1.031)\end{array}$ & $\begin{array}{l}-2.773^{* * *} \\
(1.036)\end{array}$ & $\begin{array}{l}-2.841^{* * *} \\
(1.039)\end{array}$ \\
\hline × Opp. Child & $\begin{array}{l}-1.797^{*} \\
(0.978)\end{array}$ & $\begin{array}{l}-1.818^{*} \\
(0.984)\end{array}$ & $\begin{array}{l}-1.941^{* *} \\
(0.986)\end{array}$ \\
\hline Redistribution & $\begin{array}{l}1.663^{* *} \\
(0.718)\end{array}$ & $\begin{array}{l}1.988^{* * *} \\
(0.728)\end{array}$ & $\begin{array}{l}1.965^{* * *} \\
(0.728)\end{array}$ \\
\hline × Supp. Child & $\begin{array}{l}-3.389^{* * *} \\
(0.748)\end{array}$ & $\begin{array}{l}-3.629^{* * *} \\
(0.754)\end{array}$ & $\begin{array}{l}-3.707^{* * *} \\
(0.755)\end{array}$ \\
\hline$\times$ Opp. Child & $\begin{array}{l}-1.428^{* *} \\
(0.713)\end{array}$ & $\begin{array}{l}-1.635^{* *} \\
(0.715)\end{array}$ & $\begin{array}{l}-1.757^{* *} \\
(0.720)\end{array}$ \\
\hline Payoff Difference & $\begin{array}{l}0.800^{* * *} \\
(0.115)\end{array}$ & $\begin{array}{l}0.850^{* * *} \\
(0.118)\end{array}$ & $\begin{array}{l}0.851^{* * *} \\
(0.117)\end{array}$ \\
\hline Period & & $\begin{array}{l}-0.063^{* * *} \\
(0.014)\end{array}$ & $\begin{array}{l}-0.064^{* * *} \\
(0.014)\end{array}$ \\
\hline Demographic Controls & No & No & Yes \\
\hline Observations & 2,549 & 2,549 & 2,549 \\
\hline Log-Likelihood & -671.9 & -661.3 & -656.0 \\
\hline $\begin{array}{l}\text { Notes: Standard errors in } \\
* * *(1 \%) .\end{array}$ & entheses. Sign & ance levels: & $0 \%),{ }^{* *}(5 \%)$ \\
\hline
\end{tabular}




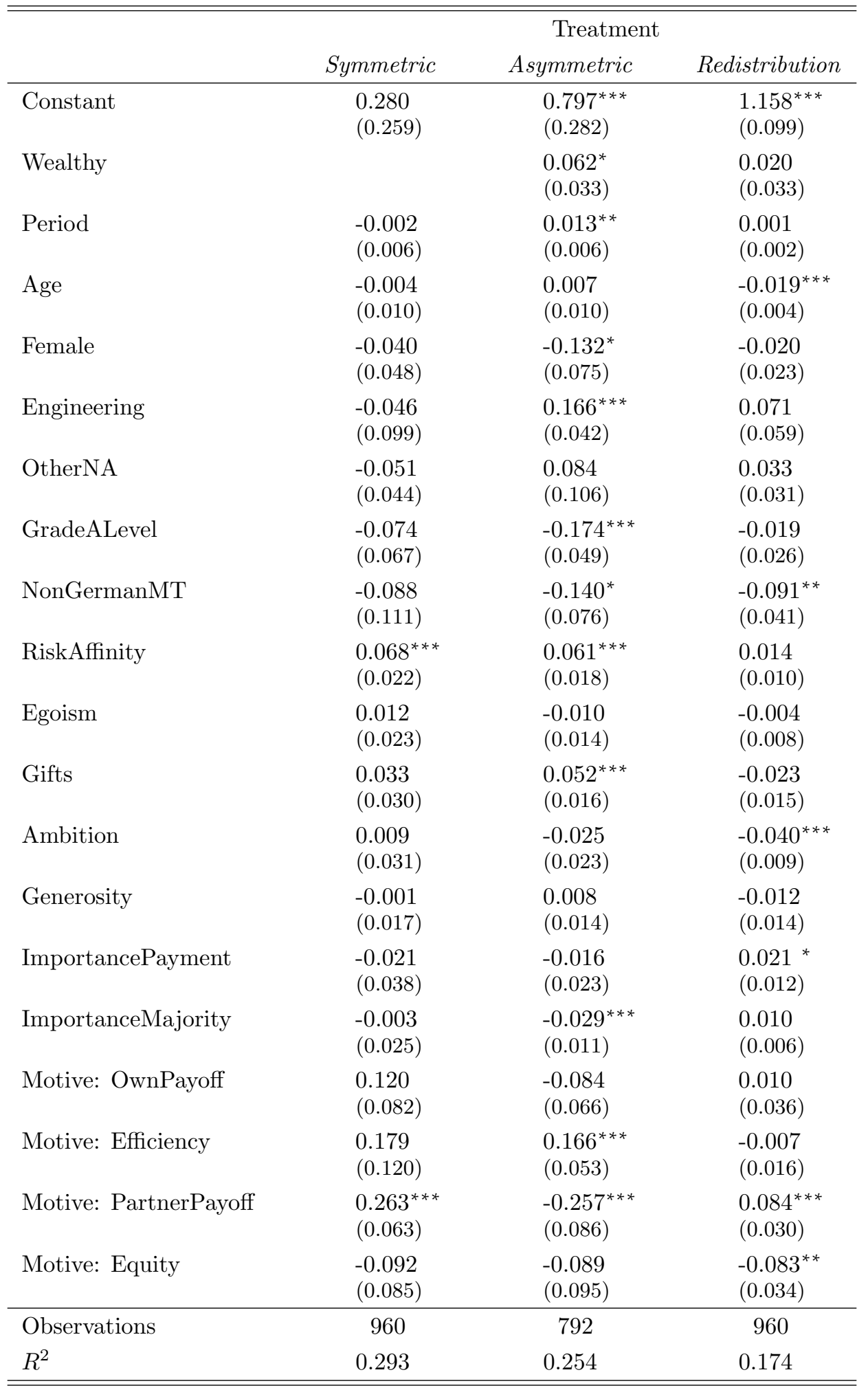

Notes: Robust standard errors in parentheses, clustered at the group level.

Significance levels: ${ }^{*}(10 \%),{ }^{* *}(5 \%),{ }^{* * *}(1 \%)$.

Table B2: Determinants of (Relative) Investment:

RANDOM-EFFECTS REGRESSION 


\begin{tabular}{|c|c|c|c|}
\hline & \multicolumn{3}{|c|}{ Treatment } \\
\hline & Symmetric & Asymmetric & Redistribution \\
\hline Constant & $\begin{array}{l}0.100 \\
(0.751)\end{array}$ & $\begin{array}{l}1.165^{*} \\
(0.625)\end{array}$ & $\begin{array}{l}2.878^{* * *} \\
(0.545)\end{array}$ \\
\hline Wealthy & & $\begin{array}{l}0.124^{* * *} \\
(0.041)\end{array}$ & $\begin{array}{l}0.066^{*} \\
(0.040)\end{array}$ \\
\hline Period & $\begin{array}{l}-0.001 \\
(0.002)\end{array}$ & $\begin{array}{l}0.029^{* * *} \\
(0.004)\end{array}$ & $\begin{array}{l}0.000 \\
(0.003)\end{array}$ \\
\hline Age & $\begin{array}{c}-0.006 \\
(0.024)\end{array}$ & $\begin{array}{l}0.004 \\
(0.020)\end{array}$ & $\begin{array}{l}-0.055^{* *} \\
(0.023)\end{array}$ \\
\hline Female & $\begin{array}{c}-0.136 \\
(0.160)\end{array}$ & $\begin{array}{l}-0.466^{* *} \\
(0.181)\end{array}$ & $\begin{array}{l}-0.083 \\
(0.118)\end{array}$ \\
\hline Engineering & $\begin{array}{l}-0.110 \\
(0.177)\end{array}$ & $\begin{array}{l}0.475^{* * *} \\
(0.142)\end{array}$ & $\begin{array}{l}0.254^{*} \\
(0.152)\end{array}$ \\
\hline OtherNA & $\begin{array}{c}-0.159 \\
(0.188)\end{array}$ & $\begin{array}{l}0.341^{*} \\
(0.205)\end{array}$ & $\begin{array}{l}0.054 \\
(0.124)\end{array}$ \\
\hline GradeALevel & $\begin{array}{c}-0.193 \\
(0.158)\end{array}$ & $\begin{array}{l}-0.433^{* * *} \\
(0.117)\end{array}$ & $\begin{array}{c}-0.088 \\
(0.110)\end{array}$ \\
\hline NonGermanMT & $\begin{array}{l}-0.151 \\
(0.222)\end{array}$ & $\begin{array}{l}-0.294^{*} \\
(0.153)\end{array}$ & $\begin{array}{l}-0.271^{*} \\
(0.154)\end{array}$ \\
\hline RiskAffinity & $\begin{array}{l}0.094^{*} \\
(0.057)\end{array}$ & $\begin{array}{l}0.096^{*} \\
(0.049)\end{array}$ & $\begin{array}{l}0.031 \\
(0.043)\end{array}$ \\
\hline Egoism & $\begin{array}{l}0.008 \\
(0.038)\end{array}$ & $\begin{array}{l}-0.005 \\
(0.041)\end{array}$ & $\begin{array}{l}-0.030 \\
(0.040)\end{array}$ \\
\hline Gifts & $\begin{array}{l}0.101 \\
(0.067)\end{array}$ & $\begin{array}{l}0.130^{* * *} \\
(0.047)\end{array}$ & $\begin{array}{c}-0.059 \\
(0.046)\end{array}$ \\
\hline Ambition & $\begin{array}{l}-0.016 \\
(0.054)\end{array}$ & $\begin{array}{l}-0.035 \\
(0.044)\end{array}$ & $\begin{array}{l}-0.156^{* * *} \\
(0.049)\end{array}$ \\
\hline Generosity & $\begin{array}{l}0.063 \\
(0.067)\end{array}$ & $\begin{array}{l}0.020 \\
(0.039)\end{array}$ & $\begin{array}{l}-0.056 \\
(0.055)\end{array}$ \\
\hline ImportancePayment & $\begin{array}{c}-0.029 \\
(0.060)\end{array}$ & $\begin{array}{l}-0.077 \\
(0.065)\end{array}$ & $\begin{array}{l}0.058 \\
(0.047)\end{array}$ \\
\hline ImportanceMajority & $\begin{array}{c}-0.027 \\
(0.037)\end{array}$ & $\begin{array}{c}-0.041 \\
(0.029)\end{array}$ & $\begin{array}{l}0.001 \\
(0.031)\end{array}$ \\
\hline Motive: OwnPayoff & $\begin{array}{l}0.269 \\
(0.184)\end{array}$ & $\begin{array}{l}-0.033 \\
(0.303)\end{array}$ & $\begin{array}{c}-0.076 \\
(0.172)\end{array}$ \\
\hline Motive: Efficiency & $\begin{array}{l}0.385^{* *} \\
(0.153)\end{array}$ & $\begin{array}{l}0.406^{* *} \\
(0.159)\end{array}$ & $\begin{array}{l}0.012 \\
(0.138)\end{array}$ \\
\hline Motive: PartnerPayoff & $\begin{array}{l}0.593^{* *} \\
(0.296)\end{array}$ & $\begin{array}{l}-0.616^{* * *} \\
(0.217)\end{array}$ & $\begin{array}{l}0.290^{*} \\
(0.156)\end{array}$ \\
\hline Motive: Equity & $\begin{array}{l}-0.269 \\
(0.201)\end{array}$ & $\begin{array}{l}-0.255 \\
(0.240)\end{array}$ & $\begin{array}{l}-0.455^{* * *} \\
(0.146)\end{array}$ \\
\hline Observations & 960 & 792 & 960 \\
\hline Log-Likelihood & -579.1 & -555.5 & -499.9 \\
\hline
\end{tabular}

Notes: Standard errors in parentheses.

Significance levels: ${ }^{*}(10 \%),{ }^{* *}(5 \%),{ }^{* * *}(1 \%)$.

Table B3: Determinants of (Relative) Investment:

RANDOM-EFFECTS TOBIT MODEL 


\section{Appendix C. Sample Instructions}

We here provide instructions for treatment Asymmetric. The instructions for the other treatments are available from the authors upon request.

\section{C.1. Instructions for Treatment Asymmetric}

For the experiment, we randomly divide the participants in groups of six. You stay with your group until the end of the experiment.

The experiment consists of $\mathbf{2 0}$ independent rounds, and each round is conducted in the same way.

\section{A. The progress of a round}

At the beginning of each round, 3 participants in each group are selected randomly and independently of the outcome of previous rounds to receive an initial endowment $A$ equal to

$$
A=600 \text { points } \text {. }
$$

The 3 remaining participants in each group receive an initial endowment $A$ equal to

$$
A=400 \text { points. }
$$

Each round consists of two parts:

- In the first part you and every other participant decide how many points to invest. You can invest each multiple of 10 points between 0 and your initial endowment (i.e. $0,10,20,30, \ldots$, or $A$ points). The payoff of your investment is determined in the second part of the round.

- At the beginning of the second part, one participant with an initial endowment of 600 points and one participant with an initial endowment of 400 points are randomly selected in each group. These two participants are called investors henceforth. Only the investments of the investors affect the payoffs in the given round. Each of the 4 remaining participants in the group is randomly matched to one of the investors as a partner. The random assignment is such that every investor is matched with exactly one participant with an initial endowment of 600 points and one participant with an initial endowment of 400 points:
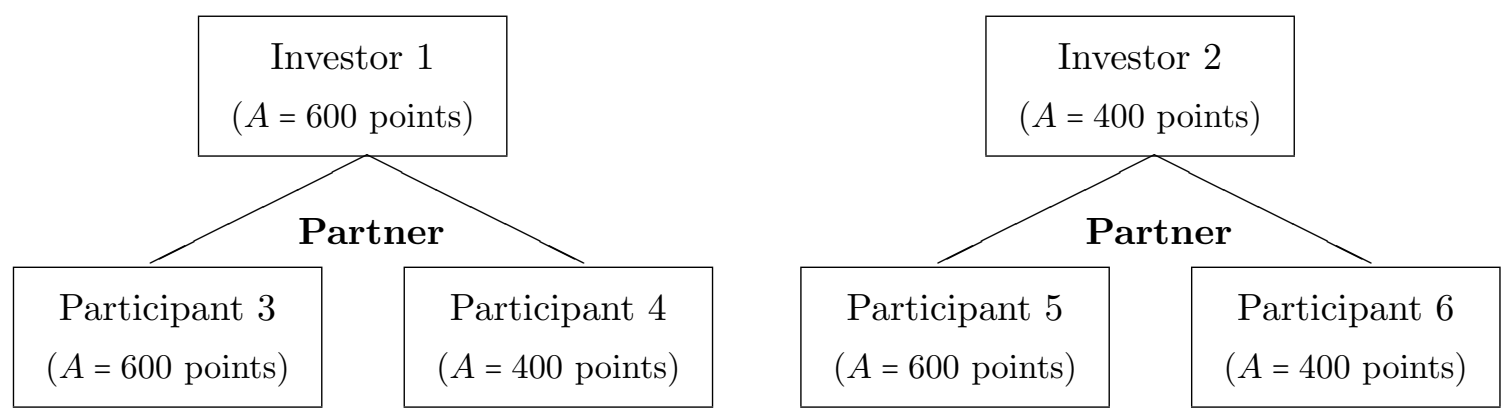
- In the second part of the experiment all 6 participants in each group vote on the approval of the two investors' investments. The investments are approved, if at least 4 participants in the group vote in favor of the investments, otherwise the investments are rejected.

\section{B. The Payoffs in a Round}

\section{Payoffs of the investors}

If you are randomly selected as an investor in a given round, your payoff $I$ in this round equals:

$$
I= \begin{cases}A+\text { your investment, } & \text { if the investments are approved. } \\ A-\text { your investment, } & \text { if the investments are rejected. }\end{cases}
$$

\section{Payoffs of the remaining group members}

If you are not selected as an investor in a given round, your payoff $I$ in this round equals:

$$
N= \begin{cases}A+0,4 \cdot \text { your partner's investment }-0,5 \cdot \text { the other investor's investment, } & \text { if investments are approved } \\ A, & \text { if investments are rejected }\end{cases}
$$

\section{Decision Support}

\section{Investment decision}

Before you decide how many points to invest, you have the possibility to test the effects of your and the other investor's decision on the payoffs in the group. Please note that your decision only affects the payoffs as indicated, if you are randomly selected as an investor.

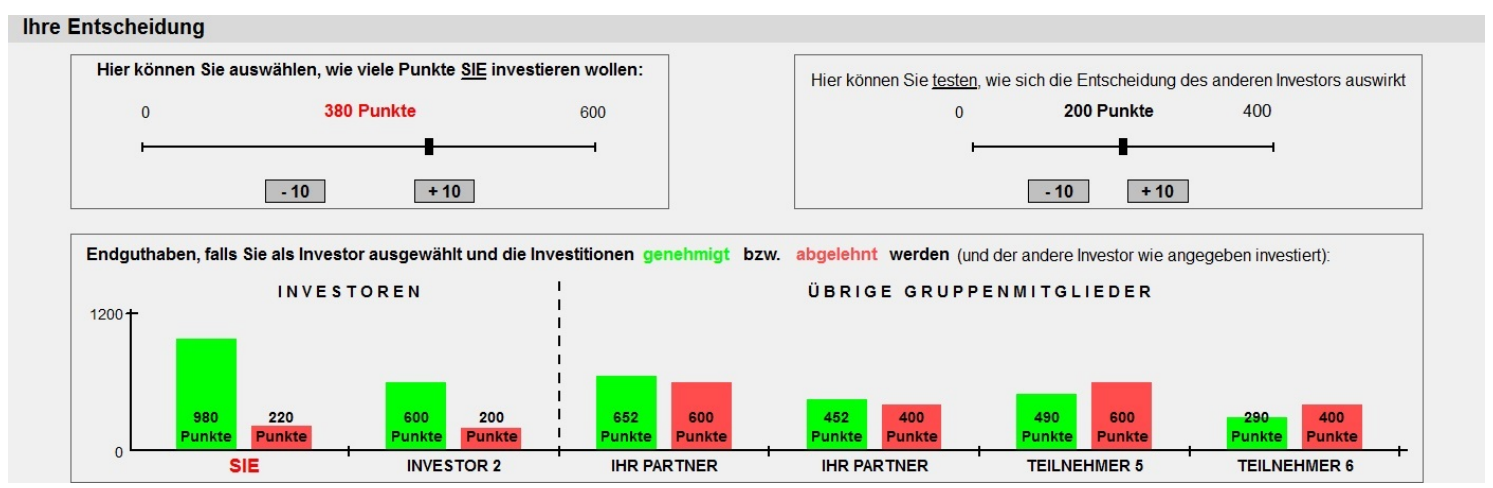

\section{Voting}

Before you cast your vote, you will be shown on your screen

(i) whether you are selected as an investor or not.

(ii) how many points you invested (if you are an investor), or how many points your partner invested (if you are not an investor).

(iii) how many points the other investor invested,

(iv) the payoffs you and the other participants in your group achieve, if the investments are approved and if they are rejected. 


\section{Earnings}

At the end of the 20 rounds, two rounds are randomly selected. The sum of the payoffs you achieved in these rounds will determine your earnings in this experiment. To select these rounds, one participant will be asked to throw a 10-sided dice twice:

- The number of points of the 1st throw determines one of the rounds $1-10$.

- The number of points of the 2 nd throw +10 determines one of the rounds $11-20$. 


\section{References}

Aввотт, F. F. (1901): A History and Description of Roman Political Institutions. Boston: Ginn \& Co.

Acemoglu, D., J. A. Robinson, and T. Verdier (2004): "Kleptocracy and Divideand-Rule: A Model of Personal Rule," Journal of the European Economic Association, $2,162-192$.

Alesina, A., And A. Passalacqua (2015): "The Political Economy of Government Debt," mimeo prepared for the Handbook of Macroeconomics edited by John Taylor and Harald Uhlig.

Alesina, A., And G. Tabellini (1990): "A Positive Theory of Fiscal Deficits and Government Debt," Review of Economic Studies, 57, 403-414.

Baron, D. P., and J. A. Ferejohn (1989): "Bargaining in Legislatures," American Political Science Review, 83, 1181-1206.

Barro, R. J. (1979): "On the Determination of Public Debt," Journal of Political Economy, 87, 940-971.

Benhabib, J., And A. Bisin (2016): "Skewed Wealth Distributions: Theory and Empirics," mimeo.

Besley, T., And S. Coate (1997): "An Economic Model of Representative Democracy," Quarterly Journal of Economics, 112, 85-114.

Boone, J., W. Müller, and S. Suetens (2014): "Naked Exclusion in the Lab: The Case of Sequential Contracting," The Journal of Industrial Economics, LXII(1), 137166.

Buchanan, J. M., and R. E. Wagner (1977): Democracy in Deficit. New York: Academic Press.

Cason, T. N., and V.-L. Mui (2007): "Communication and Coordination in the Laboratory Collective Resistance Game," Experimental Economics, 10, 251-267.

(2014): "Coordinating Resistance Through Communication and Repeated Interaction," Economic Journal, 124(574), F226-F256.

(2015): "Rich Communication, Social Motivations, and Coordinated Resistance Against Divide-and-Conquer: A Laboratory Investigation," European Journal of Political Economy, 37, 146-159.

Che, Y.-K., And K. E. Spier (2008): "Exploiting Plaintiffs through Settlement: Divide and Conquer," Journal of Institutional and Theoretical Economics, 164, 4-23. 
Cruces, J. J., and C. Trebesch (2013): "Sovereign Defaults: The Price of Haircuts," American Economic Journal: Macroeconomics, 5, 85-117.

Eavey, C. L. (1987): "Bureaucratic Competition and Agenda Control," Journal of Conflict Resolution, 33(10), 503-524.

Eavey, C. L., And G. J. Miller (1984): "Bureaucratic Agenda Control: Imposition or Bargaining?," American Political Science Review, 78(3), 719-733.

(1995): "Subcommittee Agenda Control," Journal of Theoretical Politics, 33(2), $125-156$.

Elbittar, A., A. Gomberg, and L. Sour (2011): "Group Decision-Making and Voting in Ultimatum Bargaining: An Experimental Study," The B.E. Journal of Economic Analysis \& Policy, 11(1).

Engelmann, D., and M. Strobel (2004): "Inequality Aversion, Efficiency, and Maximin Preferences in Simple Distribution Experiments," American Economic Review, 94, 857-869.

Eslava, M. (2011): "The Political Economy of Fiscal Deficits: A Survey," Journal of Economic Surveys, 25(4), 645-673.

Fischbacher, U. (2007): "z-Tree: Zurich Toolbox for Ready-made Economic Experiments," Experimental Economics, 10(2), 171-8.

Frechette, G., J. H. Kagel, and M. Morelli (2005): "Behavioral Identification in Coalitional Bargaining: An Experimental Analysis of Demand Bargaining and Alternating Offers," Econometrica, 73(6), 1893-1937.

Greiner, B. (2015): "Subject pool recruitment procedures: Organizing experiments with ORSEE," Journal of the Economic Science Association, 1, 114-25.

Irlenbusch, B., And M. Sutter (2006): "An Experimental Analysis of Voting in the Stability and Growth Pact in the European Monetary Union," Public Choice, 129, 417433.

Jullien, B. (2011): "Competition in Multi-Sided Markets: Divide and Conquer," American Economic Journal: Microeconomics, 3, 186-219.

Landeo, C. M., and K. E. Spier (2009): "Naked Exclusion: An Experimental Study of Contracts with Externalities," American Economic Review, 99(5), 1850-1877.

LARCH, M. (2012): "Fiscal Performance and Income Inequality: Are Unequal Societies More Deficit-Prone? Some Cross-Country Evidence," Kyklos, 65, 53-80. 
Messick, D. M., D. A. Moore, and M. H. Bazerman (1997): "Ultimatum Bargaining with a Group: Underestimating the Importance of the Decision Rule," Organizational Behavior and Human Decision Processes, 69(2), 87-101.

Nordhaus, W. D. (1975): "The Political Business Cycle," Review of Economic Studies, 42, 169-190.

Palfrey, T. R. (2013): "Experiments in Political Economy," mimeo prepared for the Handbook of Experimental Economics, Volume 2 edited by John Kagel and Alvin Roth.

Posner, E. A., K. E. Spier, And A. Vermeule (2010): "Divide and Conquer," Journal of Legal Analysis, 2, 417-471.

Rasmussen, E. B., J. M. Ramseyer, and J. S. J. Wiley (1991): "Naked Exclusion," American Economic Review, 81, 1137-1145.

Segal, I. R., And M. D. Whinston (2000): "Naked Exclusion: Comment," American Economic Review, 90, 296-309.

Song, Z., K. Storesletten, and F. Zilibotti (2012): "Rotten Parents and Disciplined Children: A Politico-Economic Theory of Public Expenditure and Debt," Econometrica, 80, 2785-2803.

Startz, R. (1989): "Monopolistic Competition as a Foundation for Keynesian Macroeconomic Models," Quarterly Journal of Economics, 104, 737-752.

Sutter, M. (2003): "The Political Economy of Fiscal Policy: An Experimental Study on the Strategic Use of Deficits," Public Choice, 116, 313-332.

TABellini, G. (1991): "The Politics of Intergenerational Redistribution," Journal of Political Economy, 99, 335-357.

Tabellini, G., And A. Alesina (1990): "Voting on the Budget Deficit," American Economic Reviews, 80, 37-49.

Wagner, R. H. (1986): "The Theory of Games and the Balance of Power," World Politics, 38, 546-576.

Weingast, B. R. (1995): "The Economic Role of Political Institutions," The Journal of Law, Economics and Organization, 7(1), 1-31.

(1997): "The Political Foundations of Democracy and the Rule of Law," The American Political Science Review, 91(2), 245-263.

(2005): "The Constitutional Dilemma of Economic Liberty," Journal of Economic Perspectives, 19, 89-109. 
Weingast, B. R., K. A. Shepsle, and C. Johnsen (1981): "The Political Economy of Benefits and Costs: A Neoclassical Approach to Distributive Politics," Journal of Political Economy, 89, 642-664.

Weizsäcker, R. K. v. (1992): "Staatsverschuldung und Demokratie," Kyklos, 45, 51-67.

(2015): "Repräsentative Demokratie und öffentliche Verschuldung: Ein strategisches Verhängnis," mimeo. 